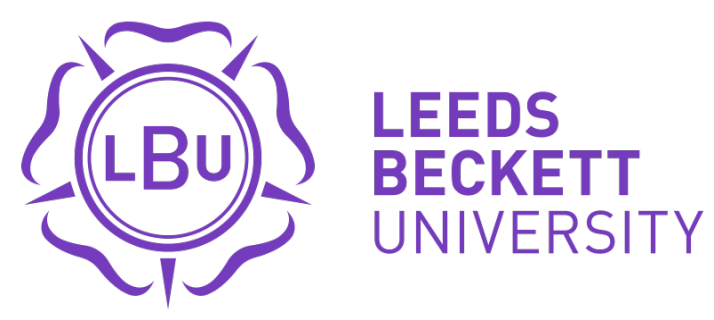

Citation:

Robertson, FA and Samy, M (2019) Rationales for Integrated Reporting Adoption and factors impacting on the extent of adoption - a UK Perspective. Sustainability Accounting, Management and Policy Journal. ISSN 2040-8021 DOI: https://doi.org/10.1108/SAMPJ-02-2019-0042

Link to Leeds Beckett Repository record:

https://eprints.leedsbeckett.ac.uk/id/eprint/5975/

Document Version:

Article (Accepted Version)

This is a post-peer-review, pre-copyedit version of an article published in Sustainability Accounting, Management and Policy Journal. The final authenticated version is available online at: http://dx.doi.org/10.1108/SAMPJ-02-2019-0042

The aim of the Leeds Beckett Repository is to provide open access to our research, as required by funder policies and permitted by publishers and copyright law.

The Leeds Beckett repository holds a wide range of publications, each of which has been checked for copyright and the relevant embargo period has been applied by the Research Services team.

We operate on a standard take-down policy. If you are the author or publisher of an output and you would like it removed from the repository, please contact us and we will investigate on a case-by-case basis.

Each thesis in the repository has been cleared where necessary by the author for third party copyright. If you would like a thesis to be removed from the repository or believe there is an issue with copyright, please contact us on openaccess@leedsbeckett.ac.uk and we will investigate on a case-by-case basis. 


\title{
Rationales for Integrated Reporting Adoption and factors impacting on the extent of adoption - a UK Perspective
}

\begin{abstract}
Purpose - This study seeks to investigate the likely adoption of integrated reporting (IR), in addition to highlighting the limitations of current reporting practices. In particular, the analysis in this study used the characteristics of diffusion of innovation theory to investigate how perceptions of IR as offering a relative advantage over existing practices; its compatibility to existing organisational values, past experiences and needs; and its perceived complexity impacted on the adoption and diffusion of IR.
\end{abstract}

Design/methodology/approach - Methodology was based on a content analysis of 22 UK FTSE 100 annual and sustainability reports across industries. To build a phenomenological triangulation research approach, semi-structured interviews were conducted with ten senior managers to ascertain their perceptions of current SR practices and IR. Findings - The analysis in this study revealed that low/medium levels of linkages exist between the majority of reports in the sample, thus limiting their usefulness. Based on these findings, this study suggests that senior managers perceive IR as having a relative advantage over existing practice. Overall, the senior managers interviewed were supportive of IR and this research revealed that many companies are starting to integrate their reporting along IR guidelines. This study further identifies factors that are likely to impact on more widespread diffusion of IR.

Research limitations/implications - The sample size to assess linkages between reports was based on a sample of company reports across industries to give a balanced view of reporting practices. This could be viewed as a limitation as it was not a representative sample of the population as a whole. Another limitation of this research study was the small sample of organisations that participated in the interview process, and the single country focus.

Practical implications - This study has identified several factors that were likely to impact on wider spread diffusion of IR, which should be of interest to practitioners in this field as well as those considering the adoption of IR. Originality/value - As an emerging phenomenon, there are few empirical studies exploring IR practices and perceptions. To the best of the authors' knowledge, this is the first paper that provides some insights into IR from a UK perspective.

\section{Introduction}

$<\mid R>$ was developed in response to growing stakeholder demands for broader, more holistic and longer-term decision-useful information, compared to that provided by traditional corporate reports (de Villiers et al., 2017). Some academics consider that $\langle\mid \mathrm{R}\rangle$ offers the potential to: shift corporate mind-sets towards alignment of profit maximisation with societal and environment wellbeing; improve the quality of information provided to stakeholders; promote sustainable business practices; and to provide the opportunity for organizations to respond to the Sustainable Development Goals (Adams, 2015; Adams, 2017a). However, others consider $<\mid R>$ to be exclusively investor orientated with little to say about either accountability or sustainability (Flower, 2015; Milne and Gray, 2013). 
While $<\mid R>$ is currently adopted globally by 1,750 organisations, IIRC's vision of it becoming the corporate reporting norm (IIRC, 2017) has been hampered by lack of clarity surrounding definitions of $<\mid R>$ and it's key concepts of value creation and integrated thinking (Dumay et al. 2017). Further difficulties encountered by $<\mid R>$ adopters include the complexity of $<\mid R>$ processes (Lodhia, 2015); competing standards (Robertson and Samy, 2015); balancing the interests of multiple stakeholders (Lodhia 2015; Parrot and Tierney, 2012) and lack of clear guidance on measurement systems and metrics for integrated thinking and reporting (Dumay et al., 2017: Feng et al., 2017; Guthrie et al., 2017; Robertson and Samy, 2015). This highlights the significance of research which aims to gain insights into \langle|$R>$ adoption rationales and factors that either help or hinder the extent of adoption.

There is a supportive regulatory environment in the UK for $<\mid R>$. A4S, founded in the UK by HRH Prince of Wales in 2004, was an early initiative to develop 'connected reporting' which influenced the development of $\langle\mid R\rangle$ (A4S, 2017). The most recent UK regulatory development by the Financial Reporting Council (FRC), the UK independent regulator responsible for promoting high quality corporate governance and reporting, has been the introduction of the strategic report, which aims to improve the relevance of narrative reports for stakeholders (KPMG, 2014). While the FRC's Guidance to the Strategic Report provides companies with assistance on how to demonstrate a holistic and meaningful picture of an entity's business model, position and prospects in a clear, concise and cohesive manner, the contents of a strategic report alone do not satisfy the content elements of an integrated report (FRC, 2014; Deloitte, 2015). However, additional information required by UK Corporate Governance Code (the corporate governance statement and directors' remuneration) combined with the strategic report broadly match the reporting content elements of the <IRF> (Deloitte, 2015). Despite these similarities, focus in the Strategic Report remains at disclosure level. $<\mid R>$ takes things further by providing a basis for linking and telling a connected story, through the process of integrated thinking (Abela, 2016; Deloitte, 2015).

As a result of these regulatory developments, recent research has shown that many larger UK organisations were starting to address some of the fundamental issues of $\langle\mid R\rangle$, albeit at a broader level (PWC, 2017; Robertson and Samy, 2015). For example, a recent UK survey found that $60 \%$ of FTSE 100 companies explained the company's key inputs and outputs that create value within their business model, but only $25 \%$ clearly integrated this model with other core reporting areas (PWC, 2017). Therefore, the UK provides a developing $<\mid R>$ arena for fruitful research. Particularly, $<\mathrm{RR}>$ studies in a UK context are scant, as highlighted by Dumay et al. (2016, p. 173) who, based on an $<\mathrm{IR}>$ literature systematic review, observe that UK research been 'rather silent" in comparison to other countries.

The significance of $<\mid R>$ empirical research is demonstrated by a growing academic interest in this area, evidenced by an increasing body of research papers appearing in leading conferences and high-ranking journals (Dumay et al. 2016). However, Dumay et al. (2016) identify that the majority of $\langle\mathrm{R}\rangle$ research does not investigate practice and individual organisations, leading to a disconnection between $<\mid R>$ academics and $<\mid R>$ practice. Particularly, prior $<\mid \mathrm{IR}>$ research on the process of adoption are sparse (Gibassier et al., 2018). While some have considered motivations for the decision to adopt $<\mid R>$ (Steyn, 2014; Higgins et al., 2014), few (e.g. Lodhia, 2015; Gibassier et al., 2018; Stubbs and Higgins, 2014) have given attention to factors influencing the extent of adoption.

To address these significant issues, the aim of this paper is to examine rationales for $<\mid \mathrm{R}>$ adoption, together with factors influencing the extent of adoption, in UK early adopters, using diffusion of innovation (DOI) as a theoretical lens. This study reports on perceptions of $<\mid R>$ adoption based on in-depth interviews with 36 senior executives actively involved in $<\mid R>$ within 17 UK organisations.

This study makes three important contributions. Firstly, it expands $<\mid R>$ research on the adoption process more broadly by considering not only rationales for the $<\mathrm{IR}>$ adoption 
decision but also factors impacting on extent of adoption. By investigating $<\mid R>$ practice in the UK, it responds to the call by Dumay et al, (2016) for $<\mid R>$ researchers to 'leave their academic ivory towers and engage more with practice' (p.176). It is the first comprehensive study of $<\mid R>$ adoption process practices in UK, where $<\mid R>$ research is scant, and adds significant knowledge by providing; an account of the reasons why early adopters have chosen to embrace $<\mid \mathrm{R}>$; an understanding of the extent of this adoption; and reasons for not fully adopted the $\langle\mathrm{RFF}>$. It further provides recommendations to inform policy and practice regarding how $\langle\mathrm{IR}>$ could be more widely adopted, and its practices further diffused, within organisations. This is important given $\langle\mathbb{R}>$ has potential to contribute to societal and environmental wellbeing.

Second, our paper enriches prior research on the adoption of management innovations where an extensive body of innovation literature has focused on the rationale for organisational adoption of management innovations but have neglected factors influencing extent of adoption (Ansari et al., 2014; Bromley et al., 2012).

Third, our paper contributes to the theoretical development of DOI theory emerging within $<\mid R>$ literature (Gunarathne and Senaratne, 2017; Robertson and Samy, 2015) by proposing a framework highlighting main themes impacting on $<\mid R>$ adoption and extent of adoption to inform future $<\mathrm{IR}>$ research.

This paper commences with a critical review of the Diffusion of Innovation (DOI) theory and subsequently presents a review of prior literature on $\langle\mid \mathrm{R}\rangle$ and innovation related to adoption and diffusion of \langle|$R>$. The research methodology used in data collection and analysis is then outlined. We subsequently present our results, followed by a discussion and conclusions drawn from the research.

\section{DOI Theory}

\subsection{Background}

Perego et al, (2016), based on a systematic review of $\langle\mathrm{IR}>$ literature, identify institutional theory as the predominant theory applied by emerging research which sought to identify key drivers underlying the adoption of $\langle\mid \mathrm{R}\rangle$ at company and country level (e.g. Jensen and Berg, 2012; Frías-Aceituno et al. 2014). However, both Jensen and Berg (2012) and Higgins et al. (2014) argue that $\langle I R>$ is not yet institutionalised, suggesting institutional theory may provide limited insights into $<\mid R>$ adoption presently. Further, institutional theory fails to consider internal factors impacting on $<\mathrm{R}>$ adoption which this study explores by engaging directly with "insiders" involved in integrated reporting to examine this phenomenon in the context in which it occurs (Crane, 1999)

Particularly, internal mind-sets can significantly influence decisions to adopt and retain new practices (Rogers, 2003). Further, most studies of institutionalization have equated the spread of something, such as a management innovation, with an indicator that it has become institutionalized, without examining the character of adoption (Scott, 2001), which this study investigates.

DOI theory has been used extensively as an analytical framework in a diversity of fields to explain how, why, and at what rate, innovations are adopted and integrated into practice (Rogers, 2003). Diffusion is a process by which innovations are communicated through certain channels, over time, among members of a social system (Rogers, 2003). Adoption takes place when members of that social system opt to acquire and use the new technologies or practice (Rogers, 2003). 
$D O I$ is emerging as a theory in $\langle\mathrm{IR}>$ literature where Robertson and Samy (2015) applied DOI theory to investigate the likely adoption of $\langle\mid R\rangle$ in the UK prior to the launch of the IIRC framework ( $<\mid R F>$ ), while Gunarathne and Senaratne (2017) examined how and why $\langle\mid R\rangle$ is diffused in Sri Lanka. This study aims to contribute to this body of literature, and further aims to fill a gap in innovation literature where a systematic review identified only $4 \%$ of studies assessing both adoption and implementation outcomes, and over half of studies failing to utilise an organizational theory to guide inquiry (Allen et al. 2017).

\subsection{Innovation Definition and Characteristics}

There are many definitions of innovation, due to its complex and multidimensional nature but, consistent with most studies on the adoption of innovation at the organisational level, we define innovation as perceived as new to the adopting organisation (Damanpour et al., 2009). Innovation can therefore relate to the development and adoption of new ideas, behaviours management practices that relate to a product, service, technology, system, policy formation, stakeholder relations or business processes at both strategic and operational levels of organisational business (Dumay et al., 2013). Therefore, innovation is both a process and an outcome (Crossan and Apaydin, 2010). In that respect, <|R> would meet this definition as it involves both new strategic business processes informed by integrated thinking and an output detailing outcomes of $\langle\mathrm{IR}\rangle$ processes in the form of an integrated report defined by a policy (the IIRC framework).

The innovation adoption process has two major phases: initiation and implementation (Rogers, 2003). The initiation stage leads to the formation of perceptions about the innovation which form the basis for a decision to adopt or reject the innovation (Agarwal and Prasad, 1997). This highlights the importance of senior executive perceptions which form the research focus of this study. $<\mid R>$ adoption requires an initiation stage of perceived needs which lead to innovative thinking. Consistent with the study by Boyne et al. (2005), we define innovation adoption as the actual organisation use of an innovation primarily because a decision to adopt does not always result in its use and indeed several prior studies have omitted this significant innovation process stage (Klein and Sorra, 1996). The implementation process emphasizes the subsequent integration of the innovation into the organisation, and consists of all events and actions which relate to modifying the innovation and the adopting organisation, the initial use of the innovation, and the continuing use of the innovation, until it becomes a routinized within the organization (Rogers, 2003). In this study, diffusion relates to the spreading of new processes to, and within, organisations.

This study focuses on perceptions of Rogers (2003) characteristics identified as having the most consistent significant relationship with the innovation adoption process, being compatibility, relative advantage, and complexity (Tornatzky and Klein, 1982). An approach on this basis has been adopted by several studies (Boyne et al., 2005; M'Chirgui and Chanel, 2006), while other studies regularly cite Tornatzky and Klein to conclude that these three attributes were consistently related to adoption behaviour (Agarwal and Prasad, 1997). This presents a strong argument for the influence these three attributes have on adoption and subsequent diffusion of innovations. The definitions of these characteristics together with emerging themes in relation to the following innovation literature review are detailed in Tables 1 (p. 8 ) and 2 (p.10).

\section{Innovation and IR Literature Review}

This section reviews prior literature on $\langle\mathrm{IR}>$ and Innovation related to the adoption and diffusion of $\langle\mid R\rangle$. $\langle\mid R\rangle$ literature was derived from the systematic review by Rinaldi et al. (2018) which draws upon academic analysis and insights published in 65 integrated reporting related articles across 83 accounting journals listed in the Scopus database. 


\subsection{Motivations for adoption - Relative Advantage}

Motivations for the adoption of new practices have two perspectives in innovation literature. Economic models draw on a rational choice perspective, pointing to economic benefits, whereas sociological models tend to adopt reputational arguments relating to growing pressures for social conformity (Ansari et al., 2010; Kennedy and Fiss, 2009). Meyer and Rowan (1977) observe that organisations confront both sociological as well as commercial expectations and that these may be incompatible.

Therefore, Kennedy and Fiss (2009) suggest that both economic and social motivations may work in parallel and be viewed as poles on a continuum, where both can explain diffusion under different conditions (Ansari et al., 2010). Therefore, decisions to adopt innovations require balancing the pursuit of social legitimacy while adhering to economic rationality (Ansari et al., 2010; Sturdy, 2004). These themes are explored as they apply to the <IR> adoption, in relation to differing perspectives and DOI theory, and are subsequently summarised in Table 1.

\subsubsection{Economic Motivations}

Rational decisions are based on considered analysis of costs and benefits and prospects of greater efficiency, particularly when organisations recognize an externally induced performance gap (Abrahamson, 1991). We propose that a perceived performance gap creates a need for change in the organisation which provides incentives to adopt innovations in order to reduce this gap (Abrahamson, 1991; Robertson and Samy, 2015). Several academics consider relative advantage as "the performance gap", defined as "perceived shortcomings of an organisation or process that may be remedied in part by adoption of the innovation" (Firth, 1996, p. 630). Particularly, Adams (2015) highlights that $<\mid R>$ overcomes the limitations of prior corporate reporting practices by encouraging organisations to "think longer term, consider what value means, to whom, and to acknowledge the role of staff, broader society and the environment in creating it" (p. 23). This view is confirmed by research which indicates that organisational executives perceive $\langle\mid \mathrm{R}\rangle$ as an approach to overcome the deficiencies associated with financial and sustainability reporting by linking the two together to improve the alignment of performance reporting against strategic aims, to better demonstrate value creation and benefit delivery, and to strengthen stakeholder engagement activity (Lueg et al., 2016; Lodhia, 2015; Parrot and Tierney, 2012; Robertson and Samy, 2015).

Particularly, Eccles and Krzus (2014) reinforce the economic benefits of better decisionmaking, identifying that \langle|$R>$ provides greater clarity about cause-and-effect relationships. Indeed, the IIRC (2013) believe the process of integrated thinking which 'leads to integrated decision-making and actions which consider the creation of value over the short, medium and long term' (p.33) will be a significant benefit to organisations. Indeed, a recent survey of senior executives found benefits of integrated thinking included: improved decision-making, both at management and board levels; enhanced information available for decision-making; and better risk management (SAICA, 2015). However, a study by Steyn (2014), based on perceptions of senior executives of South African listed companies, revealed that assessing economic value creation and strategy was not considered a key motive for companies to adopt $<\mid \mathrm{R}>$.

Relative advantage has also been expressed in other ways such as economic profitability, social benefit, and enhanced status of the organization in its industry or among its stakeholders (Tornatzky and Klein, 1982), all of which could be argued give them a relative advantage over previous competitive positions using prior innovations. An emerging body of empirical research provides evidence that $\langle\mid R\rangle$, and the effective sustainability practices it 
promotes, have positive impacts on earnings (Baboukardos and Rimmel, 2016; Eccles et al., 2014). Indeed, $<I R>$ has been shown to transform corporate processes (Phillips et al., 2011), resulting in significant cost savings from issues ranging from systems design to energy expenditure.

March (2006) observes that organisational executives adopt rational approaches when dealing with issues perceived as simple, whereas they tend to draw on a wider range of rationales when perceived complexity increases.

\subsubsection{Sociological Motivations}

Sociological models draw on reputational arguments for innovation adoption relating to growing pressures for social conformity, stemming from a desire to appear legitimate to powerful constituents, peer organisations, and/or outside stakeholders (Abrahamson, 1991; Ansari et al., 2010; Damanpour, 2014).

Damanpour (2014) differentiates sociological explanations as management innovation and management fashion perspectives which are discussed below.

\section{Management Innovation Perspectives}

The management innovation perspective assumes that organisations are adaptive systems which change due to external pressures (e.g. stakeholder demands, resource scarcity) and internal aspirations (e.g. top executives' aspiration to gain distinctive competencies and internal beliefs regarding what would enhance reputation).

\section{External Pressures}

Several $<\mid R>$ studies identify external pressures as one motivation for adoption. Specifically, some companies have adopted $<\mathrm{IR}>$ to meet stakeholder expectations (Parrot and Tierney, 2012; Lueg et al. 2016; Steyn, 2014). However, McNally et al. (2017), based on interviews of preparers in South African organisations, found that while stakeholder pressure should be a key determinant for effective $\langle\mathbb{R}\rangle$, interviewees did not identify specific changes to their accounting/performance management systems which resulted from stakeholder interactions. Further, they suggest that the usefulness of the $\langle\mathrm{IR}\rangle$ is limited because the investor community does not value the integrated report, placing more emphasis on the financial statements.

Conversely, other research identifies motivations for $\langle\mathrm{IR}>$ adoption include attracting new investors (Atkins and Maroun, 2015; Parrot and Tierney, 2012; Macias and Farfan-Lievano, 2017). Particularly, $<\mid R>$ was seen by some as a way to gain credibility in international financial markets (Atkins and Maroun, 2015; Macias and Farfan-Lievano, 2017) and/or to attract the growing number of socially responsible investors (Robertson and Samy, 2015). Indeed, Atkins et al. (2015) provide evidence of changing investor expectations due to increasing integration of social and environmental considerations into the mainstream investment process, driven by climate change agendas and increasing legislation.

Although Flower (2015) argues that $<\mid R>$ will not become the reporting norm because it lacks regulatory enforcement, most FTSE 100 companies are moving towards an $<\mathrm{R}>$ approach, encouraged by regulation, as the result of the recent introduction of the FRC requirement for a strategic report which shares similar qualitative characteristics with $<\mid R>$ (Abela, 2016; Robertson and Samy, 2015). The regulatory environment was found to motivate $<\mid R>$ adoption in South Africa, a mandated $<\mid R>$ regulatory regime, where Steyn (2014) identified compliance as a primary motive for $\langle\mid R\rangle$ adoption. Further, Silvestri et al. (2017) identified that the transition towards $<\mid R>$ of Italian family organisation was driven, to an extent, by the 
implementation in 2008 of the EU Directive 2003/51/EC while Lueg et al. (2016) identified that $<\mid R>$ adoption was motivated by the Danish government signalled preferences for $\langle\mid \mathrm{R}\rangle$ by soft-law. Particularly, the European Union Directive on non-financial reporting (2014/95/EU), is considered by Dumay et al. (2017) as a predominant external force driving European $<\mid R>$ adoption, particularly after 2017 when it came into effect. However, this legal document makes no specific mention of \langle|$R>$ and Dumay et al. (2017) highlight a number of issues that do not specifically align with the $<\mathrm{IRF}>$ in relation to the provision of specific metrics, the capitals and business model.

While the above studies predominantly consider external pressures as one driver for $\langle\mathrm{IR}\rangle$ adoption, Dumay et al. (2017) view the increase in $<\mid R>$ as being mainly driven by internal needs of organisations as $<\mid R>$ facilitates internal understanding and support for sustainability.

\section{Internal Aspirations}

Particularly, Beck et al. (2015), found that an Australian $<\mid R>$ pilot organisation had moved to pursuing strategic legitimacy through $<\mathrm{IR}>$ and integrated thinking, motivated by a crisis in public confidence, rather seeking external legitimation by following voluntary guidelines such as the GRI. Therefore, this organisation sought to restore legitimacy by defining material issues and framing the report around the business story rather than guidelines. Telling a business story was a theme identified by further research which found that $\langle\mathrm{IR}\rangle$ allowed organisations to communicate the value creation process to stakeholders more effectively than under previous reporting practices (Stubbs and Higgins, 2014; Higgins et al. 2014; Lodhia, 2015) and address accountability tensions linked to renewed strategy and changes in the corporate governance and management structure (Lai et al. 2016).

Several studies highlighted enhanced stakeholder engagement (Al-Htaybat and von AlbertiAlhtaybat 2018; Parrot and Tierney, 2012; Steyn, 2014) as a key internal drivers of IR adoption, while others identified the ability to demonstrate ethical commitment (Lodhia, 2015), to improve alignment of broader performance reporting against strategic aims (Lodhia, 2015; Macias and Farfan-Lievano, 2017; Stubbs and Higgins, 2014) and to have the ability to naturally extend an integrated thinking approach (Al-Htaybat and von Alberti-Alhtaybat 2018) as internal motivations.

Further, the competitive advantage of being an early adopter (Lodhia, 2015) and maintaining and enhancing reputation as "trend setters" in their industry (Dumay and Dai, 2017) were identified as other internal motivations for $\langle\mid \mathrm{R}\rangle$.

\section{Management Fashion Perspectives}

Management fashion perspectives, with its roots in neo-institutional theory, assume that organisations within given populations are uncertain about both their goals and the efficiency of new management innovations, and seek to reduce inherent uncertainty by economizing on search costs and looking at the experiences of peers (Tolbert and Zucker,1996). Organisations which demonstrate consistent positive outcomes from adopting innovations prompt other organisations to consider the same innovation, particularly in competitive environments (Rogers, 2003). Therefore, adoption is seen as symbolic, driven by the desire to match the practices of high-status peers, and thereby gain legitimacy (Meyer and Rowan, 1977; Scott, 2001). Jensen and Berg (2012) suggest $\langle\mid R\rangle$ is too new, and organisational adoption relatively low, to cause a bandwagon effect, where organisations mimic peers. However, a more recent research study, based on a single case study of a South African eco- 
tourism company, identified that senior executives adopted $\langle\mid R\rangle$ on the premise that legitimacy of the <IRF> was growing (McNally and Maroun, 2018).

Further, Gunarathne and Sernarantne (2017), in a Sri Lankan study, found that while early adopters had adopted $<\mid \mathrm{R}>$ on the basis of rational choice, subsequent adopters are now driven by management fashion perspectives, which are strongly influenced by active proponents of $<\mid R>$ such as professional accountancy bodies who promote awareness, identify issues and provide guidelines and training opportunities for $\langle\mid R\rangle$. Similarly, Higgins et al. (2014) identified that one motive to engage in $\langle\mid R\rangle$ is meeting expectations in two overlapping directions. Firstly, the CEO is influenced by peer-pressure to do what other peers are doing, while secondly, reporting managers experience more specific pressure from the reporting field/movement, of which they are a part.

Table 1 below provides a summary analysis of economic and sociological rationales from the differing perspectives and themes identified. Themes highlighted in bold are further themes identified from an analysis of the findings in this research study.

Table 1 Adoption Rationales and Themes

\begin{tabular}{|c|c|c|c|c|c|}
\hline $\begin{array}{l}\text { Innovation } \\
\text { Characteristic }\end{array}$ & Rationale & Perspective & $\begin{array}{l}\text { Rationale } \\
\text { Definition }\end{array}$ & Themes & Sub Theme \\
\hline \multicolumn{6}{|c|}{ Adoption Motivations } \\
\hline \multirow[t]{2}{*}{$\begin{array}{l}\text { Relative } \\
\text { Advantage - } \\
\text { perception } \\
\text { that <IR> has } \\
\text { a relative } \\
\text { advantage } \\
\text { over existing } \\
\text { practices }\end{array}$} & Economic & $\begin{array}{l}\text { Rational } \\
\text { Choice }\end{array}$ & $\begin{array}{l}\text { Considered } \\
\text { analysis of } \\
\text { costs and } \\
\text { benefits and } \\
\text { the prospects } \\
\text { of greater } \\
\text { efficiency }\end{array}$ & $\begin{array}{l}\text { Economic } \\
\text { Benefits }\end{array}$ & 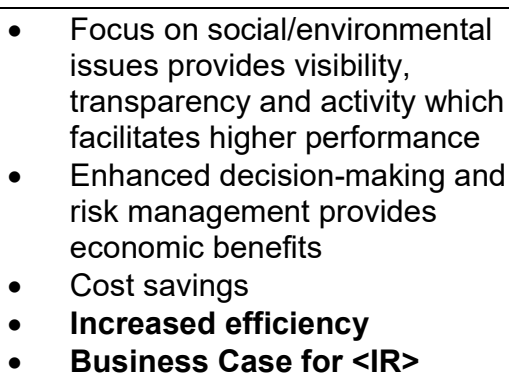 \\
\hline & Sociological & $\begin{array}{l}\text { Management } \\
\text { Innovation }\end{array}$ & $\begin{array}{l}\text { Organisations } \\
\text { are adaptive } \\
\text { systems } \\
\text { which change } \\
\text { due to } \\
\text { external }\end{array}$ & $\begin{array}{l}\text { External } \\
\text { Pressures }\end{array}$ & $\begin{array}{ll} & \text { Meet stakeholder expectations } \\
\text { - } & \text { Attract new investors } \\
\text { - } & \text { Gain credibility in international } \\
\text { - } & \text { Chancial markets } \\
\text { - } & \text { Regulatory Environment }\end{array}$ \\
\hline
\end{tabular}




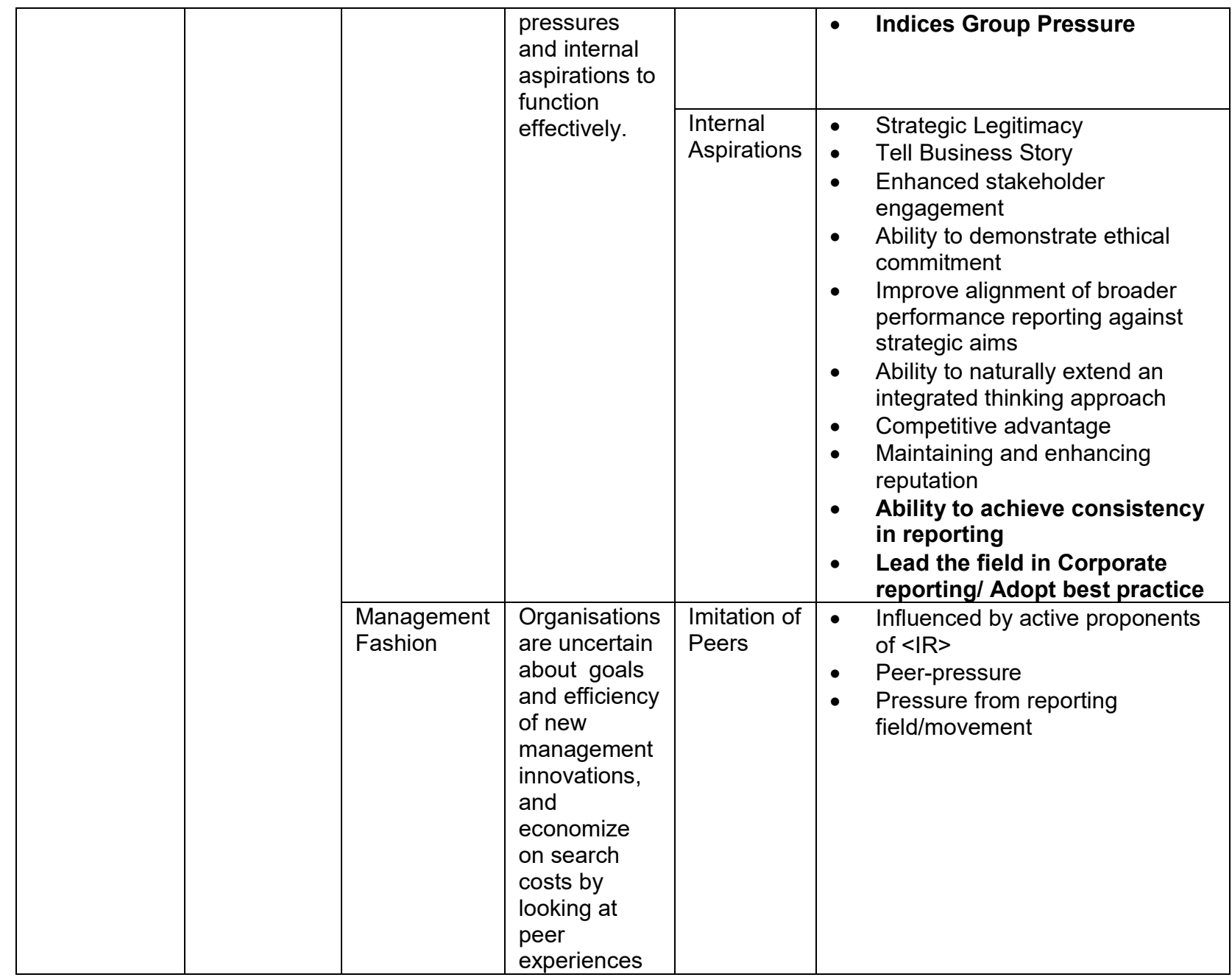

\subsection{Extent of Adoption - Incompatibility and Complexity}

While perceptions of relative advantage have a positive impact on adoption decisions, complexity and incompatibility can negatively impact on subsequent diffusion of innovations (Rogers, 2003). These innovation characteristics, as they relate to the extent of $\langle\mathrm{R} R\rangle$ adoption, are now explored.

\subsubsection{Incompatibility}

While an extensive body of innovation literature has focused on rationales for adoption, the subsequent extent of adoption has been neglected (Ansari et al., 2014; Bromley et al., 2012). Incompatibility between the new innovation and the adopting organisations' systems is likely to delay adoption, leading an organisation to implement the practice ceremonially, or to adapt the practice to improve compatibility with internal structures (Canato, et al., 2013).

Incompatibility can refer to incompatibility with the values or norms of the potential adopters or more practically may represent lack of congruence with the existing practices of adopters. Both interpretations are found to be negatively related to adoption. $<\mid R>$ studies that identify incompatibility issues are analysed below. 
Values and norms which were seen as important to facilitate $<\mathrm{R}>$ adoption were top management support (Adams, 2017b; Gunaranthe and Seneratne, 2017; Lodhia, 2015; McNally et al, 2017), a progressive culture that encourages ethical values and goals based on a combination of economic, social and environmental considerations (Beck et al. 2015; Dumay and Dai, 2017; Lueg et al. 2016; Lodhia, 2015; McNally et al, 2017), and an organisational structure that facilitates integrated thinking through cross functional groups, rather than working in separate silos (Beck et al. 2015; Gunarathe and Senaratne,2017: Lodhia, 2015; Parrot and Tierney, 2012; Stubbs and Higgins, 2014).

\section{Incompatibility with the existing practices}

Existing practices of adopters which were seen as important to facilitate $<\mid \mathrm{R}>$ adoption were competency in annual and/or sustainability reporting (Beck et al. 2015; Gunarathe and Senaratne, 2017; Lueg et al. 2016; Gunarathe and Senaratne,2017; Lodhia, 2015; McNally et al. 2017; Parrot and Tierney, 2012; Silvestri et al. 2017). However, Beck et al. (2015) warns that those with a current agenda for non-financial information may need some flexibility in $\langle\mid R\rangle$ adoption to fit their established reporting strategy.

Particularly, some studies raised concerns about the ability of existing systems and process to support <IR> (Macias and Farfan, 2017; McNally et al., 2017; Steyn. 2014; Stubbs and Higgins, 2014), resulting in high preparation costs (Chaidali and Jones, 2017) and impaired reporting quality (Atkins and Maroun, 2015; Chaidali and Jones, 2017; Gunarathe and Senaratne, 2017).

\subsubsection{Complexity}

Complexity is defined as the extent to which an innovation is perceived as difficult to understand and use (Rogers, 2003). <IR> studies that specifically highlight complexities related to $<\mid R>$ are detailed next.

Lack of clarity within the $<\mathrm{RF}>$ regarding how economic issues should be integrated with social, and environmental matters, and difficulties in managing conflicting tensions between economic, social, and environmental issues in balancing interests of multiple stakeholders in decision-making, was highlighted by several studies (Lodhia, 2015; Parrot and Tierney, 2012). Particularly, Dumay et al. (2017) argue that an unclear definition of $<\mid R>$ coupled with vague definitions of the key concepts of 'integrated thinking' and 'value creation' are barriers to $<\mathrm{IR}\rangle$ implementation. Additionally, some $<\mathrm{R}>$ studies highlight a lack of clear guidance on measurement systems and metrics for integrated thinking and reporting (Dumay et al., 2017: Feng et al., 2017; Guthrie et al., 2017; Robertson and Samy, 2015). These issues lead Dumay and Dai (2017) to argue that 'a fundamental problem with $<\mathrm{R}>$ is that the IIRC argues 'why' companies need \langle|$R>$, not 'how' to implement $\langle\mid R\rangle$, and especially not 'how' to operationalise integrated thinking' (p. 574).

It is the intention of the <IRF> to provide balance between flexibility and prescription by adopting principles-based, rather than more rigid, rules-based approaches, which recognises the need for professional judgement due to the wide variation in individual organisational circumstances and requirements. However, several academics advocate the need for further articulation and refinement of the guidelines regarding how $\langle\mathrm{IR}>$ should function in practice (Chaidali and Jones, 2017; Feng et al., 2017; Lodhia, 2015; Stubbs and Higgins, 2014).

Others highlight difficulties regarding the disclosure of forward looking information and directors' liability (Adams, 2017b; Lodhia, 2015; Steyn, 2014), determining materiality (Macias 
and Farfan, 2017; Steyn, 2014), difficulties of refining diverse data sources into a coherent single presentation of performance (Beck et al. 2015; Lodhia, 2015; Silvestri et al., 2017) and positioning $<\mid R>$ within existing corporate reporting legislation (Robertson and Samy, 2015). Themes relating to complexity and incompatibility are detailed below. Those in bold highlight additional themes identified from this research.

Table 2 Extent of Adoption Themes

\begin{tabular}{|l|l|l|}
\hline \multicolumn{1}{|c|}{$\begin{array}{c}\text { Innovation } \\
\text { Characteristic }\end{array}$} & \multicolumn{1}{|c|}{ Definition } \\
\hline Incompatibility & $\begin{array}{l}\text { Incompatibility with values } \\
\text { or norms of the adopters }\end{array}$ & $\begin{array}{l}\text { Lack of top management support } \\
\text { Culture that discourages ethical values and goals based on a } \\
\text { combination of economic, social and environmental considerations } \\
\text { Organisational structure that doesn't facilitate integrated thinking }\end{array}$ \\
\cline { 2 - 3 } & $\begin{array}{l}\text { Lack of congruence with } \\
\text { existing practices of the } \\
\text { adopters }\end{array}$ & $\begin{array}{l}\text { Incompatibility of existing systems/ processes } \\
\text { Lack of Competency in annual and/or sustainability reporting } \\
\text { Preference to adapt to company rather than <IRF> } \\
\text { requirements }\end{array}$ \\
\hline Complexity & $\begin{array}{l}\text { Lack of clarity regarding integration methodology } \\
\text { Understand } \\
\text { Unclear definitions of key concepts }\end{array}$ \\
& $\begin{array}{l}\text { Lack of clear guidance on measurement systems and metrics } \\
\text { including how < IR> might function in practice } \\
\text { Determining materiality } \\
\text { Disclosure of forward looking information and directors' liability } \\
\text { Refining diverse data sources into single performance presentation } \\
\text { Positioning, <IR> within existing legislation }\end{array}$ \\
\hline
\end{tabular}

\section{Research Methods}

This study adopts an interpretive qualitative approach which aims to add depth and comprehensiveness through analytical generalisation for understanding the $<\mathrm{IR}>$ adoption process to inform other settings rather than statistical generalisation from the setting to a population (Orlikowski and Baroudi, 1991). Particularly, Greenwood and Levin (2008), argue that " the approach of positivistic research to generalization has been to abstract from context, average out cases, lose sight of the world as lived in by human beings, and generally make the knowledge gained impossible to apply"( p. 73).

The essence of analytical generalisation is one of capturing both actors' and readers' experiences of the $\langle\mathrm{IR}>$ process and relating to them, with a focus on generalising about and to other $<\mid R>$ processes in similar or different settings (Parker and Northcott, 2016).

Given the broad, exploratory objective of the research question, with its emphasis on description and understanding from the perspectives of senior managers, in-depth interviewing was primarily employed.

Several authors emphasis the importance of engaging with practice, particularly in relation to $<\mid R>$, and related social and environment accounting practices, to establish how these practices are conceived and constructed by individuals and organisations (Adams, 2015; Dumay et al., 2016). Particularly, engagement research was employed by Stubbs and Higgins (2014), who explored the internal mechanisms employed by early adopters of $<\mid R>$ in Australia, based on 23 interviews with sustainability, finance and communication managers across 15 organisations. Similarly, Chaidali and Jones (2018) conducted interviews with 30 UK senior managers and design consultants to explore perceptions of the sources of trust as employed by the IIRC and its partners to enrol preparers into the IR initiative. 
A criterion sampling approach, as recommended by Creswell (2007) for phenomenological studies, was used. This is based on all cases meeting some criterion, which in this study was senior managers involved in $<\mid \mathrm{R}>$ practices within early adopter organisations (FTSE and Private Companies), demonstrating best practice in $\langle\mid R\rangle$. UK Integrated Reporters were identified from the IIRC database as at 31 July, 2015 and were defined by the IIRC as organisations whose reports refer to the IIRC or the $\langle\mathrm{IRF}\rangle$ or are influenced by the $\langle\mathrm{IRF}\rangle$ through participation in $<\mid R>$ Networks. 11 UK organisations were identified after exclusion of public sector and professional bodies on the basis that they ultimately may have different performance goals and motivations for $\langle\mid R\rangle$.

To ensure completeness, particularly as Robertson and Samy (2015) identified that companies presently demonstrate different stages of integration, without necessarily labelling their reports as integrated, the sample was extended to include a sample of organisations included on the IIRC database which provided examples of best practice in $\langle\mid \mathrm{R}\rangle$. It was noted that only two of the five UK pilot scheme members were listed as $<\mathrm{IR}>$ reporters but the remaining pilot companies appeared in the examples of best practice database category. The selection of this sample was based on those who demonstrated best practice in reporting through winning awards (e.g. PWC Building Public Trust Awards, IR Best Practice Awards), and also included all pilot companies within this database category.

Table 3 Population Sample

\begin{tabular}{|c|c|c|c|c|c|c|c|}
\hline & \multicolumn{2}{|c|}{$\begin{array}{l}\text { IIRC Database UK } \\
\text { Reporters }\end{array}$} & \multicolumn{2}{|c|}{$\begin{array}{c}\text { IIRC Database } \\
\text { Organisations which } \\
\text { provided examples of best } \\
\text { practice in }<\mathrm{IR}>\end{array}$} & \multirow[b]{2}{*}{$\begin{array}{l}\text { Total } \\
\text { Population } \\
(A+C)\end{array}$} & \multirow[b]{2}{*}{$\begin{array}{l}\text { Target } \\
\text { Population } \\
(B+D)\end{array}$} & \multirow[b]{2}{*}{$\begin{array}{l}\text { Total } \\
\text { Agreeing to } \\
\text { be } \\
\text { interviewed }\end{array}$} \\
\hline & $\begin{array}{l}\text { Population } \\
\text { (A) }\end{array}$ & $\begin{array}{l}\text { Included in } \\
\text { Sample (B) }\end{array}$ & $\begin{array}{l}\text { Population } \\
\text { (C) }\end{array}$ & $\begin{array}{l}\text { Included in } \\
\text { Sample (D) }\end{array}$ & & & \\
\hline \multicolumn{8}{|l|}{ Category } \\
\hline FTSE 100 & 8 & 8 & 18 & 8 & 26 & 16 & 13 \\
\hline FTSE 250 & 2 & 2 & 3 & 3 & 5 & 5 & 2 \\
\hline $\begin{array}{l}\text { Private } \\
\text { Company }\end{array}$ & 1 & 1 & 1 & 1 & 2 & 2 & 2 \\
\hline Total & 11 & 11 & 22 & 12 & 33 & 23 & 17 \\
\hline
\end{tabular}

From a total population of 33 FTSE and private companies on the IIRC database $(11<\mathrm{IR}>$ Reporters and 22 organisations demonstrating best practice), 23 were targeted $(11<\mid R>$ Reporters and 12 award winners/pilot companies) and seventeen agreed to participate in the 
research. This includes 10 of the 11 classified on the IIRC database as Integrated Reporters and 7 Award Winners and/or IIRC pilot scheme companies, identified on the IIRC database as providing examples of best practice in $\langle\mathrm{IR}\rangle$ in relation to alignment with the content elements, fundamental concepts and guiding principles of the $\langle\mathrm{IRF}\rangle$. Within the total sample were four out of the five original UK pilot scheme members.

In a phenomenological study, it is important to select individuals who have all experienced the phenomenon under investigation and therefore can articulate their experiences (Creswell, 2007). While Stubbs and Higgins (2014) targeted three groups of key actors in the $\langle\mid R\rangle$ process (sustainability, finance, communications managers), this study extended this to include legal executives due to the authors' knowledge of their involvement in the reporting process from prior research. Overall, 36 corporate senior managers agreed to participate in the research, of whom 8 were at board level. Whilst the authors recognise and identified that all adoption decisions ultimately were finalised at board level, albeit with lower level influences in many cases, they were satisfied that all interviewees were of a sufficiently senior level to have been party to rationales for adoption decisions and their interview answers reflected that knowledge. The final population sample is detailed in Table 4.

Table 4 Interviewee Analysis

\begin{tabular}{|c|c|c|c|c|c|c|}
\hline \multirow[t]{2}{*}{ Industry (REF) } & \multirow{2}{*}{$\begin{array}{l}\text { Industry } \\
\text { Category }\end{array}$} & \multirow{2}{*}{$\begin{array}{l}\text { No. of } \\
\text { Companies }\end{array}$} & \multicolumn{4}{|c|}{ No. of Interviewees (REF) } \\
\hline & & & $\begin{array}{l}\text { Finance } \\
\text { (FIN) }\end{array}$ & $\begin{array}{l}\text { Sustainability } \\
\text { (SUST) }\end{array}$ & $\begin{array}{l}\text { Communications } \\
\text { (COMMS) }\end{array}$ & $\begin{array}{l}\text { Legal } \\
\text { (LEG) }\end{array}$ \\
\hline $\begin{array}{l}\text { Utilities } \\
\text { (UP1/UP2) }\end{array}$ & Private & 2 & 3 & 2 & 1 & \\
\hline Utilities (U1/U2) & FTSE100 & 2 & 2 & 2 & 1 & \\
\hline Retail (R1/R2) & FTSE100 & 2 & 2 & 1 & 1 & 2 \\
\hline $\begin{array}{l}\text { Manufacturing } \\
\text { (M1-M6) }\end{array}$ & FTSE100 & 6 & 4 & 3 & 2 & \\
\hline Mining (MIN1) & FTSE250 & 1 & 1 & 1 & & \\
\hline $\begin{array}{l}\text { Financial } \\
\text { Services (FS1) }\end{array}$ & FTSE100 & 1 & & & 1 & \\
\hline $\begin{array}{l}\text { Communications } \\
\text { (C1) }\end{array}$ & FTSE100 & 1 & & & & 1 \\
\hline Technology (T1) & FTSE100 & 1 & & 1 & 1 & \\
\hline $\begin{array}{l}\text { Construction } \\
\text { (CON1) }\end{array}$ & FTSE250 & 1 & & 1 & 1 & 2 \\
\hline Total & & 17 & 12 & 11 & 8 & 5 \\
\hline
\end{tabular}

The interviews were conducted after a review of reports issued by the organisations over the previous 5 years, to facilitate greater understanding of \langle|$R>$ adoption within those organisations. The profile of the seventeen companies selected and their stage and level of adoption based on this review is detailed below. 
Table 5 Company Profile and Stage of Adoption 


\begin{tabular}{|c|c|c|c|c|c|c|c|c|c|}
\hline \multirow[t]{2}{*}{ Ref. } & \multirow[t]{2}{*}{ Category } & \multirow{2}{*}{$\begin{array}{l}\langle\mid \mathrm{IR}\rangle \\
\text { Reporter } \\
\text { (per IIRC } \\
\text { Database) }\end{array}$} & \multirow{2}{*}{$\begin{array}{l}\text { AR illustrates }<\mid R> \\
\text { guiding principles, } \\
\text { content elements } \\
\text { and fundamental } \\
\text { concepts (per IIRC } \\
\text { Database) }\end{array}$} & \multirow{2}{*}{$\begin{array}{l}\text { IIRC Pilot } \\
\text { Scheme } \\
\text { Member }\end{array}$} & \multicolumn{3}{|c|}{$\begin{array}{l}\text { Commencement of } \\
\text { Integration Year }\end{array}$} & \multirow{2}{*}{$\begin{array}{l}\text { Refers to } \\
\text { IIRC <IR> } \\
\text { Framework }\end{array}$} & \multirow{2}{*}{$\begin{array}{l}\text { Labels AR } \\
\text { as an } \\
\text { Integrated } \\
\text { Report }\end{array}$} \\
\hline & & & & & 2012 & 2013 & 2014 & & \\
\hline UP1 & Private & & $\checkmark$ & & & $\checkmark$ & & & $\checkmark$ \\
\hline T1 & FTSE 100 & & $\checkmark$ & $\checkmark$ & & & $\checkmark$ & & \\
\hline M1 & FTSE 100 & $\checkmark$ & & & & $\checkmark$ & & & \\
\hline MIN1 & FTSE 250 & & $\checkmark$ & & & & $\checkmark$ & & \\
\hline M2 & FTSE 100 & $\checkmark$ & & & $\checkmark$ & & & $\checkmark$ & $\checkmark$ \\
\hline CON1 & FTSE 250 & $\checkmark$ & & & & & $\checkmark$ & $\checkmark$ & $\checkmark$ \\
\hline M3 & FTSE 100 & $\checkmark$ & & & & & $\checkmark$ & $\checkmark$ & $\checkmark$ \\
\hline M4 & FTSE 100 & & $\checkmark$ & & & & $\checkmark$ & $\checkmark$ & $\checkmark$ \\
\hline R1 & FTSE 100 & $\checkmark$ & & $\checkmark$ & $\checkmark$ & & & & \\
\hline M5 & FTSE 100 & $\checkmark$ & & & $\checkmark$ & & & $\checkmark$ & $\checkmark$ \\
\hline FS1 & FTSE 100 & & 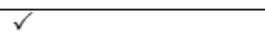 & & & $\checkmark$ & & & \\
\hline R2 & FTSE 100 & $\checkmark$ & & $\checkmark$ & $\checkmark$ & & & $\checkmark$ & $\checkmark$ \\
\hline U1 & FTSE 100 & & $\checkmark$ & & $\checkmark$ & & & & $\checkmark$ \\
\hline M6 & FTSE 100 & & $\checkmark$ & $\checkmark$ & $\checkmark$ & & & & \\
\hline U2 & FTSE 100 & $\checkmark$ & & & $\checkmark$ & & & $\checkmark$ & $\checkmark$ \\
\hline $\mathrm{C} 1$ & FTSE 100 & $\checkmark$ & & & & $\checkmark$ & & & \\
\hline UP2 & Private & $\checkmark$ & & & & & $\checkmark$ & $\checkmark$ & $\checkmark$ \\
\hline Total & & 10 & 7 & 4 & 7 & 4 & 6 & 8 & 10 \\
\hline
\end{tabular}

Although all companies have been assessed, through their inclusion in the IIRC database, as $<\mid R>$ reporters or organisations demonstrating best practice in $\langle\mid R\rangle$, the authors were interested in understanding when they commenced their $\langle\mathrm{IR}>$ journey and whether they had referred to the report as an integrated report and made reference to the $\langle\mid R F\rangle$.

While it was requested that interviews take place individually and face to face, four interviews were conducted by telephone at the interviewee's request. Additionally, one interview was conducted in a group setting with four interviewees present at the same time, at the request of participants. A semi-structured interview approach was undertaken, which allowed some structure to the interview to ensure key points were covered, but also provided flexibility to ask additional questions not anticipated at the start of the interview as new issues arose.

Interviews typically lasted between 60-90 minutes and took place between August 2015 and March 2016 after ethical approval. Focus was on rationales for adoption and factors impacting 
further implementation of $\langle\mid R\rangle$ within their organisation and interviewees were asked to identify common themes they perceived as important in explaining the $<\mid \mathrm{R}>$ adoption process with no ranking of these themes requested. All interviews were recorded and transcribed. Establishing trust is an important part of the interviewee process and therefore confidentiality was guaranteed. Organisations and interviewees are thus identified solely by industry (e.g. MIN1, CON1 - see Table 3) and job function (SUST, FIN, COMMS, LEG).

The main technique used for analysis of interviews was content analysis, which aims to describe the content of the interviews systematically and to classify the various meanings expressed in the transcribed data (Jankowicz, 2005). To aid this process, transcriptions were uploaded onto Nvivo 11 software. A thematic analysis approach was used to search for themes and patterns which occurred across the data set and involved coding data to identify themes or patterns relating to the research questions. Key themes identified are discussed in the findings section.

\section{Research Findings}

\subsection{Rationales for $<\mid \mathrm{R}>$ Adoption}

In this research, interviewees in fourteen organisations identified some form of economic rationale, and interviewees in all seventeen companies identified sociological rationales for $<\mid R>$ adoption, which were not mutually exclusive. This supports the view of March (2006) that organisational executives tend to draw on a wider range of rationales when the perceived complexity of an innovation increases. Perceived complexity of $\langle\mid \mathrm{R}\rangle$ was evidenced by the reluctance of the majority of organisations to comply fully with the $<\mid R F>$ as evidenced by a prior review of their reports, where interviewees cited reasons including the complexity and incompatibility with organisational requirements. The findings highlight, in conformance with 
the views of Ansari et al. (2010) and Sturdy (2004), that decisions to adopt an innovation are complex and multi-dimensional, including a mixture of rationales which require balancing the pursuit of social legitimacy while adhering to economic rationality.

Economic and sociological rationales are summarized below.

Figure 1

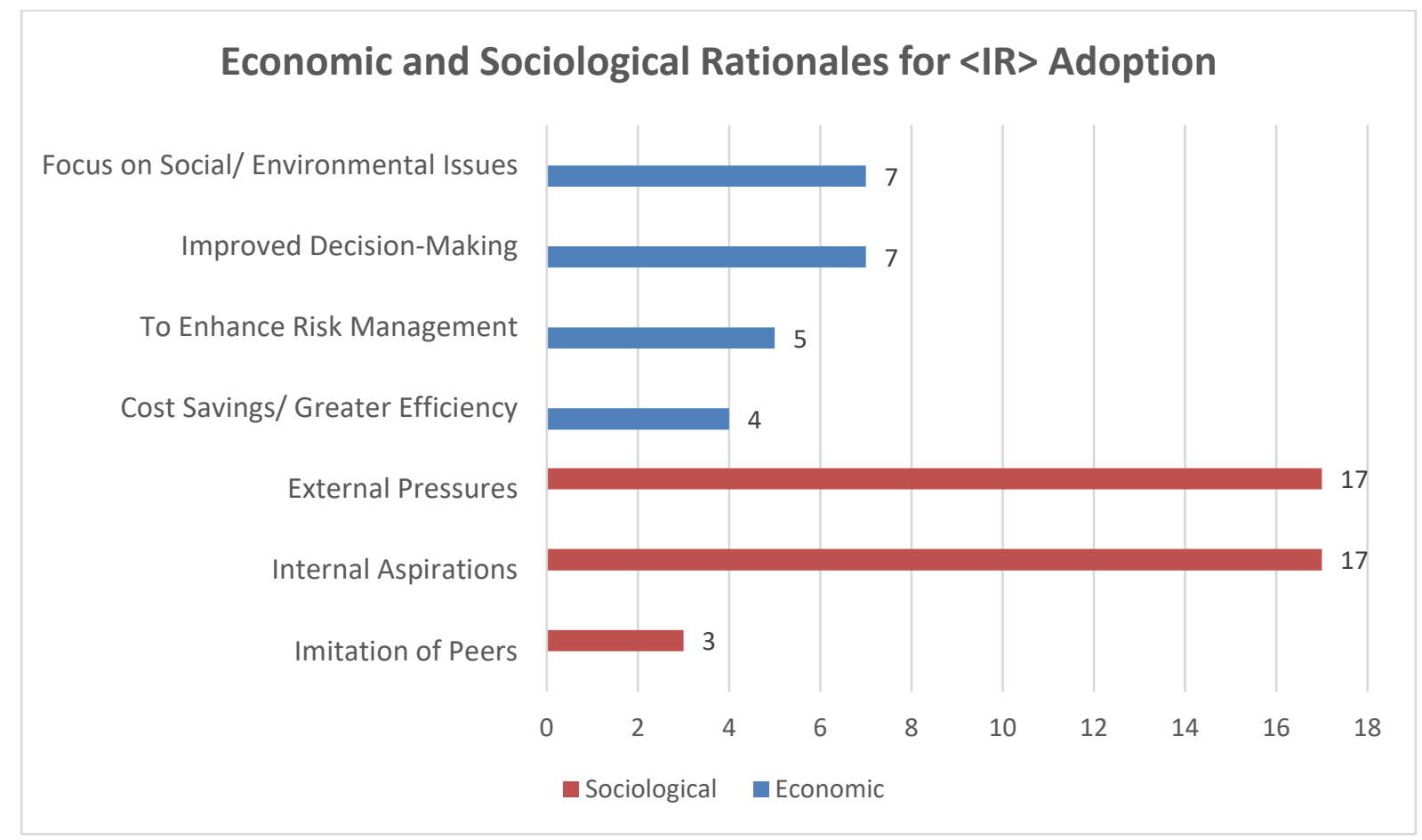

\subsubsection{Economic rationales}

Economic rationales were analysed in relation to themes emerging from the literature review (Table 1). Two predominant rationales for economic adoption of $<\mathrm{IR}>$ emerged, provision of greater focus on social and environmental issues, and improved decision-making.

\section{Greater focus on social and environmental issues}

Organisations who stated that $<\mid R>$ was adopted to provide greater focus on social and environmental issues were in utilities/manufacturing sectors, where the nature of their industry has significant impacts on the environment and society.

In those cases, $<\mid R>$ emerged as an evolutionary process that filled a performance gap as it became clear to those organisations that consideration of social and environmental elements were important to their performance and market position.

$<I R>$ to me is sustainability and how we think of, not only our traditional financial accounting, but also environmental and social aspects. As a water company, we have huge impacts, positive and negative. We want to recognize that (U2SUST).

Indeed, Parrot and Tierney (2012) observed that the context and nature of utility companies requires greater consideration of the relationship of environmental/social issues to material risk and financial health.

Particularly, the majority of these organisations identified that $\langle\mid \mathrm{R}\rangle$ provided them with a relative advantage over existing practices by allowing them to demonstrate the link between 
financial and non-financial data in longer term strategy and value creation (UP1FIN2, M2COMMS, M3SUST, U1COMMS, M6FIN, U2SUST).

Considering sustainability issues relating to our social and environmental impacts are such a key part of the sustainability of our business. We believe our sustainability practices also impact our financial and operational respondents. It's all part and parcel of doing good business for us, so really separating them from each other when, in our minds, they serve the same purposes, would be wrong. That's why we think it's more natural for us to report in an integrated way (M2COMMS).

This view is confirmed by research that indicates that organisational executives perceive $<|R\rangle$ as an approach to overcome the deficiencies associated with financial and sustainability reporting by linking the two together to improve the alignment of performance reporting against strategic aims, to better demonstrate value creation and benefit delivery, and to strengthen stakeholder engagement activity (Lueg et al., 2016; Lodhia, 2015; Parrot and Tierney, 2012; Robertson and Samy, 2015).

Significantly, one interviewee pointed out that this integrated approach may not be as strategically important in other industries:

I think it's almost that we are on the front foot naturally by the nature of our business whereas a supermarket or another commercial business might need a slightly different perspective to come up to what we recognize as important but it's very obvious for us why it's important (U2SUST).

This may explain the contradictory findings of both Frias-Aceituno et al. (2014) and Lai et al. (2016) who found that industry was not a significant driver of $<\mid R>$ adoption.

Certainly, shifts in societal thinking, as a result of the financial crisis of 2008, and growing awareness of the scarcity of resources, have put additional pressures on these organisations to effectively manage their environmental and societal impacts to ensure their longer-term survival. Particularly, failure to do this may result in significant economic impacts, in terms of reputational damage and fines, as was seen with BP and Volkswagen.

Four of these interviewees also emphasised that a clear business case for $<|\mathrm{R}\rangle$ was important to their adoption decision:

We're not in the business of being responsible for its own sake. Don't get me wrong, we care but we are a company. We're not an NGO, we're not a charity. So we need to be able to demonstrate that being responsible is not only the right thing but the rational thing to do in business terms (U1COMMS).

This rationale has now been incorporated into Table 1 as an additional rationale for adoption.

\section{Improved Decision-making}

The other dominant economic rationale given for adoption (seven organisations) was that $<\mid R>$ was seen as a means of improving decision-making through integrated thinking.

Interviewees in four organisations (TISUST, M2COMMS, CON1COMMS, U2FIN) identified that they were already adopting integrated thinking by embedding their sustainability practices into business strategy, therefore $<\mid R>$ allowed them to demonstrate this through their reporting practices:

When people say 'do <IR>', first we need to do integrated thinking. We were already doing it, so $<I R>$ did not make us do integrated thinking, we were already doing that. <IR> made us think about how we explain what we were doing (U2FIN). 
Others, in three organisations (U1COMMS, M6FIN, UP1SUST), saw <IR>, and the related process of integrated thinking, as a means of facilitating a broader, more holistic approach to decision-making that gave them a relative advantage over existing practices by overcoming the siloed approach to decision-making:

Improved decision-making is the ultimate objective. We need to manage our risks and consider more holistic information so we can make better decisions (UP1SUST).

Particularly, Eccles and Krzus (2014) identify better decision making as one of the main benefits of $\langle\mid \mathrm{R}\rangle$, as it: provides greater clarity about cause-and-effect relationships, eliminates thinking in silos and results in a more effective and efficient execution of long-term strategies.

\section{Enhanced Risk Management}

Interviewees in five companies (T1SUST, M3SUST, M4FIN, U1COMMS, UP2SUST) identified that \langle|$R>$ was adopted to enable them to effectively manage risks affecting longer term business sustainability and/or to demonstrate that to stakeholders:

There is a clear awareness that the material risks to our business go beyond financial figures. So $<I R>$ enables you to start thinking in a more holistic way (M3SUST).

Indeed, a recent survey of senior executives in South Africa found benefits of integrated thinking included better risk management (SAICA, 2015). However, the benefits of effective risk management are likely to take time to emerge, due to the longer term focus of $\langle\mid R\rangle$.

\section{Cost savings/greater efficiency}

According to some, $<\mathrm{R}>>$ can drive organisational change toward more sustainable outcomes and transform corporate processes (Eccles and Krzus, 2014; Phillips et al., 2011), resulting in the realisation of significant cost savings. However, fewer interviewees organisations (UP1SUST, UP1FIN1, M1FIN, R1FIN, U1COMMS) identified this rationale for $<\mid R>$ adoption, which related mainly to the efficiencies of combining reports and refining systems:

It's about how you set up to report because it's part of a whole. What we're trying to achieve is more efficient business management. What we're trying to do is to integrate that more because what we've recognized is we've had a lot of different systems running (M1FIN).

However, one organisation was able to identify a significant cost saving in terms of energy use:

$<I R>$ has a direct business consequence such as saving electricity. We have the biggest array of solar panels in the whole of Europe thus cutting consumption of electricity significantly. That is good for business as well, because it's cutting costs, but it's doing it in the right way (R1FIN).

This demonstrates that consideration of environmental factors can have a positive impact on economic value which lends support to the findings of an emerging body of empirical research which provides evidence that $\langle\mid R\rangle$, and the effective sustainability practices it promotes, have a positive impact on earnings (Baboukardos and Rimmel, 2016; Eccles et al., 2014).

\subsubsection{Sociological Rationales}

When organisations are uncertain about the effectiveness of new management innovations, economic forces for adoption diminish, and sociological forces, primarily to satisfy external pressures and gain reputation, take precedence (Damanpour, 2014). Indeed, Steyn (2014) found that sociological motivations for $\langle\mathrm{IR}>$ adoption were predominant in her study of South African CEO/CFO perceptions of $\langle\mid \mathrm{R}\rangle$. 
Sociological rationales were analysed from themes emerging from the literature review: external pressures, internal aspirations and imitation of peers (Table 1). All company interviewees identified some form of external pressure and internal aspiration as an $\langle\mid R\rangle$ adoption rationale, while three interviewees perceived imitation of peers as a motivation. These were broken down into further sub-themes, shown below.

Figure 2

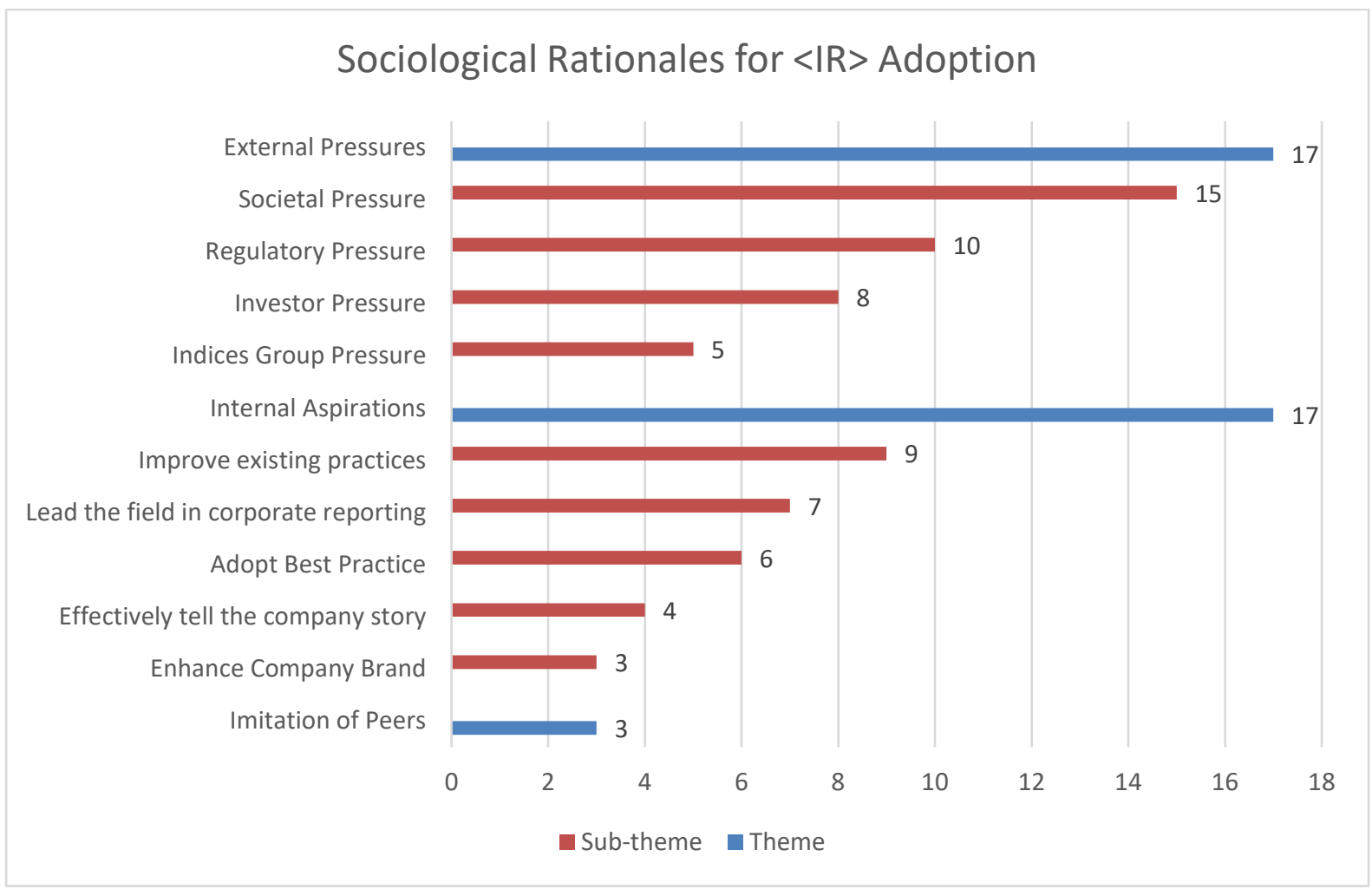

The predominant sociological reasons for adoption were external pressures and internal aspirations.

\section{External Pressures}

All companies identified some form of external pressure with four predominant themes emerging being: societal; investor; indices group; and regulatory pressures. The predominant pressure was societal, identified by interviewees in fifteen organisations.

Particularly, seven organisations (UP1COMMS, M1COMMS, M4FIN, R2SUST, U1COMMS, M6FIN, UP2SUST) perceived that shifts in societal expectations following the 2008 financial crisis and several high profile financial scandals had influenced $<\mid R>$ adoption:

Adoption of $<I R>$ has probably been helped by various scandals in the recent past. Particularly with the crash and all the financial scandals over the last ten years, the view has evolved that purely financial reporting doesn't really reflect what is going on, particularly on the reputational side $(M 4 F I N)$.

Therefore, eight interviewees (UP1SUST, UP1FIN3, T1SUST, MIN1FIN, M3SUST, (M4SUST, U2FIN, C1LEG) believed that $<I R>$ enabled them to meet the societal expectations of their stakeholders:

Our external stakeholders really do think that our impact in society is a huge risk to our business, so we need to address that through adopting a more holistic approach (MSSUST). 
Additionally, nine interviewees (UP1COMMS, T1SUST, M1SUST, M1COMMS, M3SUST M4SUST, U1COMMS, U1COMMS, U2SUST) identified that meeting stakeholder needs through a more holistic approach enabled them to demonstrate the future sustainability of their business:

Climate change, population growth, all these pressures on society are also pressures on the sustainability of our business, so there isn't really a separation and so to report on them as a whole makes sense (UP1COMMS).

Indeed, several prior IR studies identified meeting stakeholder expectations as a rationale for adoption (Parrot and Tierney, 2012; Lueg et al. 2016; Steyn 2014).

Fewer interviewees identified a pressure from investors to adopt $\langle\mid R\rangle$. This pressure was mainly to satisfy increasing demands for greater integration of financial and non-financial information (M1COMMS, MIN1SUST, CON1LEG, M3SUST, M4FIN, R1FIN, U1COMMS):

We are seeing more and more investor inquiries about how, at a global level, we are sustainable, and how we are able to protect our core business. Sitting around this are nonfinancial factors, so we have to be able to articulate them properly and $\langle I R>$ is one way of doing that (M1COMMS).

Indeed, Atkins et al. (2015) provide evidence of changing investor expectations due to increasing integration of social and environmental considerations into the mainstream investment process, driven by climate change agendas and increasing legislation.

A related area influencing $<\mid R>$ adoption was meeting the information requirements from ethical investment index organisations (MIN1SUST, M2COMMS, CON1SUST, M3SUST, U2SUST):

The indices, the DJSI and ftse4good will rank us higher for the good work we do socially so that is one driver for including more of that information in the annual report (MSSUST).

Gaining a high rating on sustainability indices is an aspiration of organisations keen to enhance their reputation. Particularly, shares of companies listed on Dow Jones Sustainability Indices are recommended for sustainability investing, therefore attracting the rapidly growing socially responsible investment (SRI) market (Atkins et al., 2015).

Another predominant pressure (ten companies) was regulation. For companies in the utilities sector (UP1FIN2, U1FIN, U2SUST, U2FIN, UP2SUST), the highly regulated nature of their industry meant that consideration of society, and the environment, are essential elements to their business. Therefore $\langle\mathrm{R}>$ was seen as a superior mechanism to allow them to demonstrate their commitment regarding these three elements to regulators:

I think the nature of the business that we are, our subject matter lends itself more readily to $<I R>$ and the regulatory model that's wrapped around it, which does drive us to talk about our environmental performance, our social performance, customer service performance, and the like (U2SUST).

For other companies (M1COMMS, MIN1FIN, CON1LEG, M3SUST, U1FIN, U2SUST,U2FIN C1LEG, R2SUST), recent changes in the regulatory regime in the UK, particularly around governance and non-financial reporting requirements (the strategic report guidelines) were influential in decisions to adopt $\langle\mid \mathrm{R}\rangle$, in order to keep ahead of regulation:

We were about to do $\langle I R>$, and it was the year that narrative reporting came in. You also had mandatory carbon and diversity reporting. So we said, even if we're not doing it, we will be forced to do $60-70 \%$ of it through UK regulation anyway (R2SUST).

However, one interview warns of the dangers of compliance-led reporting: 
There's a regulatory regime which is helping drive the right behaviours to some degree, but what we must not do is just think that responsibility equals delivering a regulatory contract, because then you will never find new opportunities that go above and beyond where, actually, it's right to do so (U2SUST).

Indeed, IR takes things beyond compliance led regulation by providing a basis for linking and telling a connected story, through the process of integrated thinking (Abela, 2016).

\section{$\underline{\text { Internal Aspirations }}$}

Internal aspirations were identified by all organisations as a driver for adoption of $\langle\mid R\rangle$, and covered five themes.

Interviewees in nine organisations (UP1COMMS, T1COMMS, MIN1FIN, M1SUST, M1COMMS, R1FIN, R2SUST, FS1COMMS, U1COMMS, U2SUST) perceived adoption as a means of improving existing practice, particularly in achieving consistency, accountability and transparency in reporting:

We wanted to demonstrate in that very difficult environment that we were a company that deserved membership in the human race, for a start. And we moved on from there. (U1COMMS).

So really what we are trying to achieve is that in all the communications that go to our stakeholders, there is consistency (T1COMMS).

The aspiration to improve communications by telling the organisational story (four organisations) (T1COMMS, MIN1FIN, M3SUST, C1LEG), was a theme identified by other studies who found that \langle| $\mathrm{R}>$ allowed them to communicate the value creation process to stakeholders more effectively than under previous reporting practices (Beck et al. 2015; Higgins et al. 2014; Lodhia, 2015; Stubbs and Higgins, 2014):

I think the purpose for us is that $<I R>$ tells the story of the business and explains how the business is run. It allows you to explain the relationship between our activity, our risk and our ambitions for the future (T1SUST)

Another predominant theme (seven organisations)) was a desire to be seen as leading the field in corporate reporting ((UP1SUST, M1COMMS, MIN1FIN, U2FIN, CONLEG1, M3SUST, C1LEG):

We were 1 of only 2 or 3 FTSE100 companies to go early on IR. I don't want to be a leader in everything, but where stuff is sensible in a way shareholders want it, then I want to be leading. (U2FIN)

Related to this, interviewees in six organisations (UP1COMMS, UP1SUST, M1SUST, M2COMMS, M4FIN, U1FIN, U2SUST) adopted $<I R>$ because it was seen as best practice:

It's best practice and we like to follow best practice. I can certainly see this as a mechanism to help society understand our business without giving away commercially sensitive information (M1SUST).

Further, three interviewees (R2SUST, C1LEG, UP2SUST) identified enhancing the company brand as an $<\mid R>$ adoption rationale:

Our chief marketing officer is very keen on us talking about brand in term of capturing people's emotions. He was quite keen, in all our external facing materials, marketing or communications 
and reports, that we should be telling a narrative story that is more than just money and numbers (C1LEG).

Indeed, the competitive advantage of being an early adopter (Lodhia, 2015) and maintaining and enhancing reputation as "trend setters" in their industry (Dumay and Dai, 2017) were identified as internal motivations for $\langle\mid \mathrm{R}\rangle$ in other studies. Indeed, reputational benefit is seen to be a key motive for listed South African companies for adoption of $\langle\mid \mathrm{R}\rangle$, secondary only to compliance. Therefore, Steyn (2014) suggests that $\langle\mathrm{IR}\rangle$ is perceived by managers as an effective tool for legitimizing corporate activities.

\section{$\underline{\text { Imitation of Peers }}$}

Imitation of Peers, particularly in relation to adopting practices prevalent in leading FTSE organisations, was identified by interviewees in three organisations (FS1COMS, M4FIN, M4SUST, C1LEG) as an <IR > adoption motivation:

We looked to see what our peers are doing and particularly the quality of companies in the original pilot scheme was an influence (FS1COMMS).

Similarly, Higgins et al. (2014) identified that one motive to engage in $<\mid R>$ was the CEO being influenced by peer-pressure to do what others are doing, and/or the reporting manager experiencing pressure from their reporting field/movement.

\subsection{Extent of Adoption}

We argue that the extent of $\langle\mathrm{IR}>$ adoption is an important factor to explore in addition to identifying adoption decision rationales, as it provides a richer, more in-depth aspect to the research, particularly as Klein and Sorra (1996) identify that increasingly, organisational analysts identify implementation failure, not innovation failure, as the cause of many organisations' inability to achieve the intended benefits of the innovations they adopt' (p.1055). Particularly, there is a dearth of $\langle\mid R\rangle$ research considering extent of adoption (Gibassier et al., 2018).

A detailed review of the reports (Table 5) highlights that seven organisations $(41 \%)$ commenced their \langle|$R>$ journey in 2012 (prior to the issue of the $\langle\mid R F\rangle$ ), four started integrating social, financial and environmental data within their AR in 2013, with the remainder (six organisations) adopting $<\mid R>$ in 2014 . While all organisations were clearly integrating financial and non-financial data within their report, as evidenced by their inclusion in the IIRC database, and are adopting many of the principles of $\langle\mathrm{IR}\rangle$, seven of the seventeen companies $(41 \%)$ in this sample have chosen not to label their report as an Integrated Report. As one interviewee states:

I don't think we're going to badge it as an Integrated Report this year. Only a few companies have actually been bold enough to do that (M2COMMS).

Additionally, nine of the seventeen companies (53\%) chose not to refer to the $\langle\mid R F\rangle$, shown below, despite the sample consisting of those within the IIRC database labelled as either $\langle\mathrm{IR}\rangle$ reporters or organisations that demonstrated best practice in $\langle\mid R\rangle$. 


\section{Organisational Compliance with IIRC Framework}

Interestingly, the sample includes four of five of the original IIRC pilot scheme (UK), of which only one chose to label their report as an integrated report. This company is also the only original pilot scheme member to refer to the $\langle\mathrm{IRF}\rangle$. This was surprising to the authors, who had assumed that all pilot schemes companies were full adopters of the $\langle\mid \mathrm{RF}\rangle$.

Indeed, Matt Chapman, head of KPMG UK's Better Business Reporting Group, suggests that while many organisations may not be referring to the framework, they are paying attention to it stating, "we won't see $<\mathbb{R}>$ adopted in name, but we will see a lot of its principles being adopted under different guises" (Orton-Jones, 2015, p.36). The authors therefore sought to understand why this was the case.

Significantly, only three companies (18\%) stated compliance with the <IRF> (or the principles of the \langle|$R F>$ ) in their report.

A further five companies (29\%) stated they were 'aligning' rather than 'complying' with the $<$ RF $>$ while nine companies (53\%) made no mention of $<\mathrm{IRF}\rangle$ in their AR. Reasons cited by these fourteen companies for stating only alignment (five organisations) or making no mention of the $<\mid R F>$ (nine organisations) are summarised below. 
Figure 4

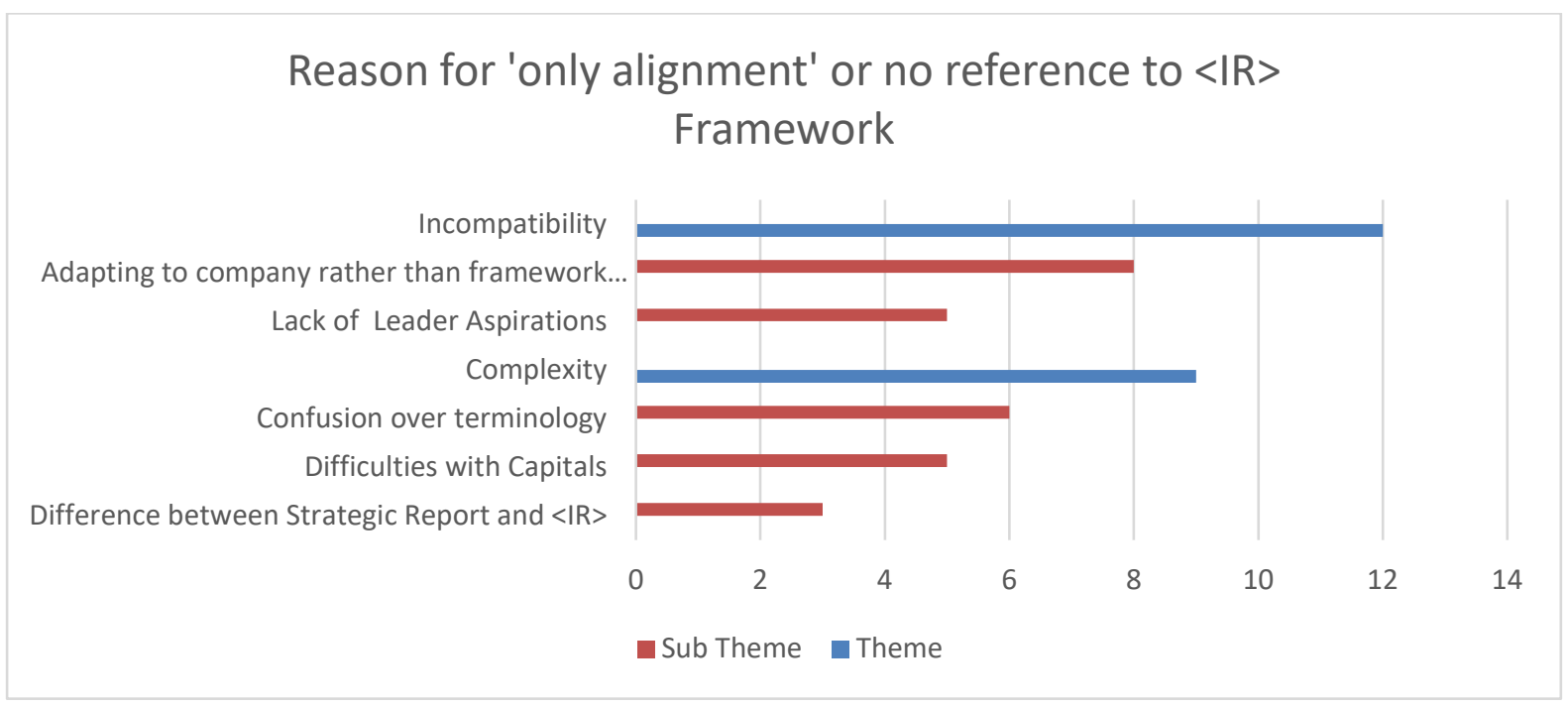

Less extensive implementation is referred to as 'decoupling' or surface-level adoption, where implementation is symbolic rather than substantive (Bromley et al., 2012) or as 'selective emulation', where adopters choose not to implement certain conflicting features of the practice (Westney, 1987). A review of organisational reports prior to the interviews revealed no evidence of symbolic practice, as was found by Stubbs and Higgins (2014), where four organisations had issued a 'combined report', which merely reports on financial and nonfinancial data without demonstrating the connectivity of data required of a full integrated report. All reports reviewed by the author clearly demonstrated attempts at connectivity between financial and non-financial data.

Two main predominant themes emerged which impacted on full $<\mid R>$ adoption, firstly, an incompatibility with organisational requirements and secondly, perceptions of complexity of the $<\mid R F>$.

\subsubsection{Incompatibility}

The predominant reason given for not stating compliance with the $<\mid R F>$ (12 organisations) were lack of leadership aspirations (4 organisations) or a preference to adapt to company rather than $<\mathrm{IRF}>$ requirement (8 organisations). 
Interviewees in four organisations stated lack of leadership aspirations led to not fully adopting the <IRF> (T1COMMS, MIN1, R2FIN, M1COMMS):

I don't want to be leading edge and I can't be taking the risks, but once the risks are proven, I am next in (T1COMMS).

Top management support (Adams, 2017b; Gunaranthe and Seneratne, 2017; Lodhia, 2015; McNally et al, 2017) is seen as essential for $<\mid R>$ adoption, and for this cost/benefits need to be perceived. In particular, three of these interviewees identified no perceived cost benefits of $<|R\rangle$ which may be due to the longer-term nature of $\langle\mid R\rangle$ :

You have to invest an awful lot into something that doesn't necessarily seem like it's going to garner an awful lot of favour. There's perhaps no sense in being a first mover on that (M1COMMS).

Several interviewees (UP2SUST, R2SUST, M4SUST) view <IR> as a journey.

We definitely are aspiring towards the framework requirements but we need to consider what elements are relevant to our business and I think we have come a fair way on the journey, but there are still elements we'd like to work with (UP2SUST).

Similarly, Stubbs and Higgins (2014) identified that $<\mid R>$ Implementation in Australian early adopters led to incremental, rather than radical changes to processes and structures. Particularly, some studies raised concerns about the ability of existing systems and process to support <IR> (Macias and Farfan, 2017; McNally et al. 2017; Steyn, 2014; Stubbs and Higgins, 2014), resulting in high preparation costs (Chaidali and Jones, 2017). Other studies found that a progressive culture that encouraged values consistent with <lR> (Beck et al. 2015; Dumay and Dai, 2017; Lueg et al. 2016; Lodhia, 2015; McNally et al, 2017) and an organisational structure that facilitates integrated thinking (Beck et al. 2015; Gunarathe and Senaratne, 2017: Lodhia, 2015; Parrot and Tierney, 2012; Stubbs and Higgins, 2014) facilitated $<\mid R>$ adoption. However, changes to culture, organisational structures and processes can take time.

Others (UP1SUST, T1SUST, M1COMMS, M6FIN, C1LEG, M5SUST, FS1COMMS), while they may view $<\mid R>$ as a journey, are using the $<\mid R F>$ as it fits with their company needs, particularly around the six capitals:

We don't lavishly follow the framework and I think it's fairer to say we are moving that way as fits our business needs and that's kind of our intention (C1LEG).

"We felt that there was confusion regarding the capitals, and some did not fit with our business model and strategy. That was another reason for not adopting the framework fully. We took what was relevant to our business" (FS1COMMS).

Particularly, the $<\mid R F>$ does not require $<\mid R>$ to be structured along the lines of the capitals, and states that the main objective for capital inclusion within the $\langle\mathrm{IRF}\rangle$ is to serve as a theoretical underpinning for the concept of value creation and a guideline for ensuring organisations consider all the forms of capital they use or affect (IIRC, 2013). Indeed, recent research into the reporting strategies of UK FTSE 100 reveals that most are only starting to consider the impact the company's activities have on their material capitals (IIRC, 2015).

Some (U1COMMS, UP2SUST, M4FIN) allude to using the $<\mid R F>$ as it fits their business in conjunction with other frameworks: 
It's not GRI reporting, it's not IIRC reporting, it's just our own company reporting and what we do is borrow all the best and respond to what we need to be doing and what we need to be communicating to our stakeholders (U1COMMS).

Indeed, Beck et al. (2015) warns that those with a current agenda for non-financial information might may require flexibility in $<\mathrm{IR}>$ adoption to fit their established reporting strategy. Indeed Lodhia (2015), in his research of an Australian bank, notes that while the bank reports were integrated and followed IIRC principles, they were based on a structure which suited the bank, thus facilitating an innovative rather than 'box ticking' approach to reporting. Particularly, in our experience, based on involvement with the ICAS Corporate Reporting Committee which includes members from the FRC and leading accountancy firms, UK regulation encourages innovative rather than compliance-led reporting.

It is the intention of the $\langle\mathrm{IRF}>$ to 'strike an appropriate balance between flexibility and prescription which recognizes the wide variation in individual circumstances of different organisations while enabling a sufficient degree of comparability across organisations to meet relevant information needs' (IIRC, 2013, p.4). However, by providing flexibility, full adoption of the $<\mathrm{RRF}>$ may take time within UK organisations, as they attempt to establish a fit with their own individual circumstances on an incremental basis.

\subsubsection{Complexity}

The second predominant reason for not stating compliance with the $<\mathrm{IRF}>$ ( 9 organisations) related to \langle|$R>$ complexity, particularly a lack of clarity surrounding the definition of $\langle\mid R\rangle$ and the complexity of certain aspects of $\langle\mathrm{IR}\rangle$. Confusion over terminology/definition (UP1FIN2, T1SUST, M1COMMS, FS1SUST, M6FIN, R2SUST), the capitals (FS1COMMS, M1FIN, M1COMMS, U1SUST, C1LEG) and differences between $<\mathrm{IR}>$ and the strategic report were three themes emerging.

Particularly a confusion regarding the definition of $\langle\mathrm{IR}>$ was evident:

There's been a lot of controversy about what $<I R>$ is and maybe it's one of the reasons why I don't say, "I'm aspiring to this framework." To me, it's about what makes sense for the organization (UPFIN2).

It may be that many organisations' perceive that the definition is still evolving and changing as alluded to by one interviewee.

We are not jumping at it because it's still changing very quickly. It's a bit like Betamax or VHS, we don't want to jump on it only to find it's something else (UP2SUST).

Indeed, Dumay et al. (2017) argue that an unclear definition of $<\mid \mathrm{R}>$ coupled with vague definitions of the key concepts of 'integrated thinking' and 'value creation' are barriers to $<\mathrm{IR}>$ implementation.

The IIRC concept of six capitals was another area causing confusion.

The capitals are where I had a problem, because nobody understands the capitals as described, I mean manufacturing capital, I still don't understand that one (U1SUST). 
Other $<\mid \mathrm{R}>$ studies highlight a lack of clear guidance on measurement systems and metrics for integrated thinking and reporting (Dumay et al., 2017: Feng et al., 2017; Guthrie et al., 2017; Robertson and Samy, 2015).

Another issue, mentioned by interviewees ((MIN1FIN, M1FIN, UP1FIN1), which is UK specific, is confusion over the difference between $<\mid R>$ and the Strategic report which is mandatory in the UK:

When $\langle I R>$ came out two or three years ago, people would start talking about $<I R>$ and by the time you got to the end of the sentence, you'd be talking about a strategic report. There was a lot of confusion as to the differences between the two (MIN1).

Although the FRC draws attention to the fact that the $<|R F\rangle$ and the Guidance on the Strategic Report encourage similar qualitative characteristics, $\langle\mid R\rangle$ is differentiated from the strategic report by integrated thinking and the underlying internal processes impacted by it (Deloitte, 2015). The danger is that those who adopt the strategic report guidelines without consideration of the wider requirements of $\langle\mid R\rangle$, will fail to realise the benefits of integrated thinking, particularly the potential of $\langle\mathrm{R}\rangle\rangle$ to shift the mind-sets of corporate actors to better align notions of profit maximisation with societal/environmental wellbeing.

\section{Discussion, Conclusion and Recommendations}

We sought to understand rationales for $<\mid R>$ adoption and factors impacting on the extent of adoption in UK early adopters of $\langle I R>$, using DOI as a theoretical lens. While IR has rapidly captured the attention of regulators, organisations, stakeholders and accounting scholars in both positive and negative ways (e.g. Adams, 2015; Rinaldi et al., 2018; Flower, 2015;), little is known about the views of early adopters and the practical adoption of IR within organisations, particularly in a national setting (Chaidali and Jones, 2017; Dumay et al. 2016). Particularly, research into $<\mid R>$ adoption decision motivations and subsequent extent of adoption are scant, especially in the UK. To address this knowledge gap, we conducted interviews with senior executives involved in the <IR> process in UK early adopter organisations to add depth and richness to the ongoing debate.

We have argued that DOI is a useful theory for determining factors that impact on the broader adoption process. We assert that considering the overall adoption process, to include extent of adoption is particularly important as Klein and Sorra (1996) identify that increasingly, organisational analysts identify implementation failure, not innovation failure, as the cause of many organisations' inability to achieve the intended benefits of the innovations they adopt', (p.1055). Organisations who fail to fully embraced $<\mid R>$ may not reap its intended benefits which is significant, given the potential of $\langle\mid R\rangle$ to shift corporate mind-sets towards alignment of profit maximisation with societal/ environment wellbeing and sustainable development goals.

Our study enriches prior research on the adoption of management innovations where an extensive body of innovation literature has focused on the rationale for organisational adoption of management innovations, but has neglected the subsequent extent of adoption of these practices (Ansari et al., 2014; Bromley et al., 2012).

Our research contributes to the theoretical development of DOI theory emerging within $\langle\mid \mathrm{R}\rangle$ literature (Gunarathne and Senaratne, 2017; Robertson and Samy, 2015) through the proposal of a framework highlighting themes identified from $<\mid R>$ literature, through the lens of DOI theory, impacting on $<\mathrm{IR}>$ adoption and extent of adoption. We have built on this framework by identifying additional themes arising as a result of this research (Tables 1 and 2 , highlighted in bold) which are discussed further below. This framework could inform future 
$<\mid R>$ research through analytical generalisation in similar or different settings relating to $<\mid R>$ adoption processes (Parker and Northcott, 2016).

This section concludes on the key findings, and contributes to policy and practice, given the findings, by providing recommendations on how $<\mid R>$ adoption may be further enhanced in the future.

The study revealed that adoption decisions incorporated both economic and sociological rationales, with sociological rationales taking greater predominance. When organisations are uncertain about the effectiveness of new innovations, economic forces for adoption diminish, which suggests that reduced complexity, enhanced by further guidance from the IIRC, particularly around how $<\mathrm{R}>$ might be practically implemented (e.g. clear guidance on measurement systems and metrics), may increase economic motivations. Particularly, in the UK, having a business case for \langle|$R>$ and increased efficiency of combining reports and refining systems were additional factors influencing $<\mid R>$ adoption.

In this research, economic $<\mid R>$ adoption decisions were predominantly to provide enhanced focus on environmental and social issues for organisations in industries with significant environmental/societal impacts (which in this study were utilities and manufacturing industries), and improved decision-making. The results suggest early adopters, who choose to adopt to improve decision-making, are likely to be organisations required to address risks related to their significant societal/ environmental impacts and would benefit from enhanced decisionmaking through consideration of the longer term implications of the inter-relationship between financial, environmental and societal concerns. They are either already adopting an integrated thinking approach and therefore $<\mid R>$ represents a means of demonstrating this practice more visibly, or they perceive $<\mathrm{IR}>$ as offering a more holistic approach to decision-making, which is essential for them to effectively manage societal and environmental as well as financial risks impacting on their longer term sustainability and performance. Therefore $<|\mathrm{R}\rangle$ provided them with a relative advantage over existing practices by allowing them to demonstrate the link between financial and non-financial data in longer term strategy and value creation, which they perceived would lead to improved decision-making and risk management processes.

Although subsequent adopters tend to adopt due to social influence, subsequent adopters may also adopt $<\mid R>$ if they perceive an economic advantage in doing so. Therefore, further research into the economic benefits of $\langle\mid \mathrm{R}\rangle$, and the communication of this to opinion leaders, is encouraged to further enhance $<\mid R>$ adoption.

However, it may take several years for the benefits of $\langle\mathrm{IR}\rangle$ to emerge in the UK due to its longer term focus on value creation, particularly as UK adopters to date have, at the earliest, commenced their \langle|$R>$ journey in 2012 and are taking an incremental rather than radical approach to adoption. Particularly, changes to organisational culture, structures and process that facilitate $<\mid R>$ can take time to evolve.

Sociological reasons for adoption, which tend to take precedence when organisations are uncertain about the effectiveness of new management innovations, were predominant in this research. Particularly, interviewees in all organisations identified some form of external pressure to adopt $\langle\mid R\rangle$, with the predominant pressure being societal, reflecting a shift in societal expectations of organisational accountability following the financial crisis, and several high profile financial scandals. Further, regulatory pressure, particularly in relation to industry (Utilities Sector) and recent changes in the regulatory regime in the UK and Europe, around governance and non-financial reporting requirements, were influential in $\langle\mid R\rangle$ adoption decisions, particularly in order to keep ahead of regulation. An additional external pressure for $<\mathrm{IR}>$ adoption, identified in the UK context, was from ethical investment index organisations whose ratings have an impact on reputation and attracting socially responsible investment. 
All organisations identified that \langle|$R>$ allowed them to meet the internal aspirations of their organisation, predominantly through adoption of best practice and leading the field in corporate reporting which were adoption influences unique to the UK setting based on research to date. Improving existing practice to meet the needs of a broader range of stakeholders was also deemed important and therefore $<\mid R>$ offered a relative advantage over existing practices by allowing them to more effectively engage with broader stakeholder groups, resulting in lower reputational risk.

Reputation can have a significant impact on company value, demonstrated by the 2015 UK Reputation Dividend Report which found, for the average FTSE 100 Company, a 1\% improvement in reputation adds about $£ 266$ million to its market value (Reputation Dividend, 2015). Therefore, larger and higher profile companies, whose reputation could be significantly damaged by negative stakeholder perceptions, are likely to be the early adopters of $\langle\mid R\rangle$, which is confirmed by the greater number of FTSE 100 companies included on the IIRC database as $\langle\mathrm{R}\rangle>$ reporters. As subsequent adopters tend to mimic early adopter opinion leaders, peer organisations who are influenced by these organisations may be next to adopt.

Management fashion perspectives based on imitation of peers, particularly in relation to adopting practices prevalent in leading FTSE organisations, was identified by interviewees in fewer companies as a driver for $\langle\mathrm{IR}$ adoption which is unsurprising given that $\langle\mathrm{R}\rangle$ is a relatively new and evolving concept. However, subsequent adopters may now be driven by a management fashion perspective, which is strongly influenced by high status peers (FTSE 100 early adopters) and active proponents of $\langle\mathrm{IR}\rangle$ such as professional accountancy bodies who promote awareness, identify issues and provide guidelines and training opportunities $>$ for $\langle\mid \mathrm{R}\rangle$. Therefore, to increase adoption of $\langle\mid \mathrm{R}\rangle$, the IIRC should continue to seek active training providers and professional body partners.

However, further adoption may be hampered by the lack of visibility of $\langle\mathrm{IR}\rangle$ adopters, given that nine out of the seventeen companies $(53 \%)$ sampled chose not to refer to the <lRF.

The extent of $\langle\mid \mathrm{R}\rangle$ adoption, in compliance with the $\langle\mathrm{IRF}\rangle$, was hampered by incompatibility and complexity.

The authors suggest that the perceived complexity of $<\mid \mathrm{R}$ may be reduced by further guidance regarding: how key concepts of $\langle\mid \mathrm{R}\rangle$ might be applied in practice; definition of $\langle\mid \mathrm{R}\rangle$; use of the capitals and their measurement; further definitions of these capitals; and further clarity on how the \langle| $\mathrm{RF}>$ relates to the FRC Strategic report, to facilitate further adoption of the $\langle\mid R F\rangle$.

Incompatibility with organisational needs was cited by interviewees in twelve organisations. Indeed, a preference to adapt to company rather than $\langle\mathrm{RF}\rangle$ requirements was identified as an additional factor affecting the extent of adopting the $<\mid F R>$. However, many view $<\mid R>$ as a journey where successful adaptation requires a co-evolution between the organisation and $\langle\mid R\rangle$, so that $\langle\mid R\rangle$ is adapted to fit the unique characteristics of an organisation, but also the organisation needs to evolve to benefit from the lessons learned from $\langle\mid R\rangle$, which takes time. This time may be reduced by further guidance on how the <IRF> may fit with specific industry requirements, as was implemented by the GRI (https://www.globalreporting.org/standards/sector-guidance/Pages/default.aspx).

As integrated reporting was in its early adoption stage at the time of research, the authors hope that the insights into early adopters in the UK, and recommendations made lead to further adoption of \langle| $\mathrm{R}>$ over time. Adams (2015) highlights that $\langle\mathrm{IR}>$ offers a bold and worthy approach, which has the potential to lead to profound change. We, as researchers, should be part of that change, by engaging with practice, including our own institutions, to create new insights and creative solutions as the $<\mathrm{IR}>$ journey evolves. 
Further studies are required with organisations undertaking IR across different countries, and with a wider range of internal and external stakeholders, to further understand the factors which help or hinder IR diffusion in different contexts. Comparative studies in several country settings may provide further insight into unique country-specific drivers and inhibitors of IR, in addition to commonalities between countries.

\section{References}

A4S (2012), "The value of extra financial disclosure", available at: https://www.accountingforsustainability.org/en/knowledge-hub/reports/value-financialdisclosure.html

Abela, M. (2016), "Integrated Reporting in the UK.", available at: http://gather.london/wpcontent/uploads/2016/03/8.1.7 White-Paper-Integrated-Reporting v3.pdf

Abrahamson, E. (1991), "Managerial Fads and Fashions: The Diffusion and Rejection of Innovations", Academy of Management Review, Vol.6 No.3, pp.586-612.

Adams, C. (2017a), The Sustainable Development Goals, integrated thinking and the integrated report, ICAS:IIRC, London.

Adams, C. (2017b), "Conceptualising the contemporary corporate value creation process", Accounting, Auditing \& Accountability Journal, Vol. 30 No.4, pp.906-931.

Adams, C. (2015), "The International Integrated Reporting Council: A call to action", Critical Perspectives on Accounting, Vol.27 (March), pp.23-28.

Adams, C. and Larrinaga-González, C. (2007), "Engaging with organisations in pursuit of improved sustainability accounting and performance", Accounting, Auditing \& Accountability Journal, Vol. 20 No. 3, pp. 333-355.

Agarwal, R. and Prasad, J. (1997), "The role of innovation characteristics and perceived voluntariness in the acceptance of information technologies", Decision Sciences, Vol.28 No.3, pp. 557-582.

Al-Htaybat, K and von Alberti-Alhtaybat, L. (2018), "Integrated thinking leading to integrated reporting: case study insights from a global player", Accounting, Auditing \& Accountability Journal, https://doi.org/10.1108/AAAJ-08-2016-2680

Allen, J. D. et al. (2017), "Measures of organizational characteristics associated with adoption and/or implementation of innovations: A systematic review", BMC Health Services Research, Vol.7 No.1, pp.591-601.

Ansari, S. M., Reinecke, J., and Spaan, A. (2014), "How are practices made to vary? Managing practice adaptation in a multinational corporation", Organization Studies, Vol.35 No.9, pp. 1313-1341.

Ansari, S., Fiss, P., and Zajac, E. (2010), "Made to fit: How practices vary as they diffuse", Academy Of Management Review, Vol.35 No.1, pp.67-92.

Atkins, J., Atkins, B. C., Thomson, I. and Maroun, W. (2015), "“Good" news from nowhere: Imagining utopian sustainable accounting", Accounting, Auditing and Accountability Journal, Vol.28 No.5, pp.651-670. 
Atkins, J. and Maroun, W. (2015), "Integrated reporting in South Africa in 2012: Perspectives from South African institutional investors", Meditari Accountancy Research, Vol. 23 No.2, pp. 197-221.

Baboukardos, D. and Rimmel, G. (2016), "Value relevance of accounting information under an integrated reporting approach: A research note", Journal of Accounting and Public Policy, Vol. 35 No.4, pp.437-452.

Beck, C., Dumay, J., and Frost, G. (2015), "In pursuit of a 'single source of truth': from threatened legitimacy to integrated reporting", Journal of Business, Vol.141 No.1, pp.191-205.

Boyne, G.A., Gould-Williams, J.S., Law, J., and Walker, R.M. (2005), "Explaining the adoption of innovation: An empirical analysis of public management reform", Environment and Planning: Government \& Policy, Vol.23 No.3, pp.419-435.

Bromley, P., Hwang, H., and Powell, W. (2012), "Decoupling revisited: Common pressures, divergent strategies in the U.S. nonprofit sector”, M@n@gement, Vol.15, pp.468-501.

Canato, A., Ravasi, D., and Phillips, N. (2013), "Coerced practice implementation in cases of low cultural fit: Cultural change and practice adaptation during the implementation of Six Sigma at 3M", Academy of Management Journal, Vol.56 No.6, pp.1724-1753.

Chaidali, P. and Jones, M. J. (2017), "It's a matter of trust: Exploring the perceptions of Integrated Reporting preparers", Critical Perspectives on Accounting, Vol.48, pp.1-20.

Chesley, J., and Wenger, M. (1999), "Transforming an Organization: Using Models to Foster A Strategic Conversation”, California Management Review, Vol.41 No.3, pp.54-73.

Crane, A. (1999), "Are you ethical? Please tick yes or no. On researching ethics in business organizations", Journal of Business Ethics, Vol. 20 No. 3, pp. 237-248.

Creswell, J.W. (2007), Qualitative Inquiry and Research Design, $2^{\text {nd }}$ ed, Sage, Thousand Oaks, C.A.

Crossan, M.M., and Apaydin, M. (2010), "A multi-dimensional framework of organizational innovation: A systematic review of the literature", Journal of Management Studies, Vol.47 No.6, pp.1154-1191.

Damanpour, F. (2014), "Footnotes to Research on Management Innovation", Organization Studies, Vol.35 No.9, pp.1265-1285.

Damanpour, F., Walker, R.M. and Avellaneda, C.N. (2009), "Combinative effects of innovation types and organizational performance: A longitudinal study of services organizations", Journal of Management Studies, Vol.46 No.4, pp.650-675.

Deloitte (2015), "<IR>: how does it fit into the UK corporate reporting landscape?", available at: https://www.iasplus.com/en/publications/uk/other/ir-uk-landscape

de Villiers, C., Hsiao, P.-C.K. and Maroun, W. (2017), "Developing a conceptual model of influences around integrated reporting, new insights, and directions for future research", Meditari Accountancy Research, Vol. 25 No. 4, pp. 450-460.

Dumay, J., Bernardi, C., Guthrie, J. and La Torre, M. (2017), "Barriers to implementing the International Integrated Reporting Framework: A contemporary academic perspective", Meditari Accountancy Research, Vol.25 No.4, pp.461-480. 
Dumay, J. and Dai, T. (2017), "Integrated thinking as a cultural control?", Meditari Accountancy Research, Vol.25 No.4, pp.574-604.

Dumay, J., Bernardi, C., Guthrie, J., and Demartini, P. (2016), "Integrated reporting: A structured literature review", Accounting Forum, Vol.40 No.3, pp.166-185.

Dumay, J., Rooney, J., and Marini, L. (2013), "An intellectual capital-based differentiation theory of innovation practice", Journal of Intellectual Capital, Vol.14 No.4, pp.608- 633.

Eccles, R.G., Ioannou, I and Serafeim, G. (2014), "The Impact of Corporate Sustainability on Organizational Processes and Performance”, Management Science, Vol.60 No.11, pp.28352857.

Eccles, R., and Krzus, M P. (2014), The Integrated Reporting Movement: Meaning, Momentum, Motives, and Materiality, 1st ed., Wiley. ISBN: 978-1-118-64698-4

Feng, T., Cummings, L. and Tweedie, D. (2017), "Exploring integrated thinking in integrated reporting - an exploratory study in Australia", Journal of Intellectual Capital, Vol.18 No.2, pp. 330-353

FRC (2014), Guidance on the Strategic Report, FRC, London.

Firth, M. (1996), "The diffusion of managerial accounting procedures in the People's Republic of China and the influence of foreign partnered joint ventures" Accounting, Organisations and Society, Vol.21 No.7-8, pp.629-654.

Flower, J. (2015), "The International Integrated Reporting Council: A story of failure", Critical Perspectives on Accounting, Vol.27 (March), pp.1-17.

Frias-Aceituno, J., Rodríguez-Ariza, L., and Garcia-Sánchez, I. (2014), "Explanatory Factors of Integrated Sustainability and Financial Reporting", Business Strategy and the Environment, Vol.23 No.1, pp.56-72.

Gibassier, D., Rodrigue, M. and Arjalies, D.-L. (2018), '“Integrated reporting is like God: no one has met Him, but everybody talks about Him": The power of myths in the adoption of management innovations', Accounting Auditing \& Accountability Journal, Vol.31 No.5, pp. $1349-1380$.

Greenwood, D.J. and Levin, M. (2008), "Reform of the social sciences and of universities through action research", in Denzin, N.K. and Lincoln, Y.S. (Eds), The Landscape of Qualitative Research, 3rd ed., Sage Publications Inc., Thousand Oaks, CA, pp. 57-86.

Gunarathne, N, and Senaratne, S. (2017), "Diffusion of integrated reporting in an emerging South Asian (SAARC) nation", Managerial Auditing Journal, Vol.32 No.4/5, pp.524-548.

Guthrie, J., Manes-Rossi, F. and Levy-Orelli, R. (2017), "Integrated reporting and integrated thinking in Italian public sector organisations", Meditari Accountancy Research, Vol. 25 No.4, pp. 553-573.

Higgins, C., Stubbs, W., and Love, T. (2014), "Walking the talk(s): Organisational narratives of integrated reporting", Accounting, Auditing \& Accountability Journal, Vol.27 No.7, pp.10901119.

IIRC (2017) International Framework Implementation Feedback Summary report, IIRC, London.

IIRC (2015), Integrated Reporting. How does it fit in the UK? IIRC, London. 
IIRC (2013), The International <IR> Framework. IIRC, London.

Jankowicz, A.D. (2005), Business Research Projects, Thomson. London.

Jensen, J., and Berg, N. (2012). "Determinants of Traditional Sustainability Reporting Versus Integrated Reporting. An Institutionalist Approach" Business Strategy and the Environment, Vol.21 No.5, pp.299-316.

KPMG (2014), A Practical Guide to the Strategic Report, KPMG, London.

Kennedy, M.T., and Fiss, P.C. (2009), "Institutionalization, framing, and the logic of TQM adoption and implementation decisions among U.S. hospitals", Academy of Management Journal, Vol.52 No.5, pp.897-918.

Klein, K.J., and Sorra, J.S. (1996), "The challenge of innovation implementation", Academy of Management Review, Vol.21 No.4, pp.1055-1080.

Lai, A., Melloni, G., and Stacchezzini, R. (2016), "Corporate sustainable development: Is 'Integrated Reporting' a legitimation strategy?" Business Strategy and the Environment, Vol.25 No.3, pp.165-177.

Lodhia, S. (2015), "Exploring the transition to integrated reporting through a practice lens: An Australian customer owned bank perspective", Journal of Business Ethics, Vol.129 No.3, pp.585-598.

Lueg, K., Lueg, R., Andersen, K., and Dancianu, V. (2016), "Integrated reporting with CSR practices", Corporate Communications: An International Journal, 21 No.1, pp.20-35.

M'Chirgui, Z., and Chanel, O. (2006), "New product adoption and use: The case of the Moneo electronic purse", Management of Innovation and Technology, IEEE International Conference, Vol.2 No.1, pp.637-641.

Macias, H. A. and Farfan-Lievano, A. (2017), "Integrated reporting as a strategy for firm growth: multiple case study in Colombia", Meditari Accountancy Research, Vol. 25 No.4, pp. 605-628.

March J. (2006), Rationality, foolishness and adaptive intelligence", Strategic Management Journal, Vol.27 No.3, pp.201-214.

McNally, M. A. and Maroun, W. (2018), "It is not always bad news: Illustrating the potential of integrated reporting using a case study in the eco-tourism industry", Accounting, Auditing \& Accountability Journal, https://doi.org/10.1108/AAAJ-05-2016-2577.

McNally, M. A., Cerbone, D. and Maroun, W. (2017), "Exploring the challenges of preparing an integrated report”, Meditari Accountancy Research, Vol. 25 No.4, pp.481-504.

Meyer, J., and Rowan, B. (1977), "Institutionalized organizations: Formal structure as myth and ceremony", American Journal of Sociology, Vol.83 No.2, pp.340-363.

Milne, M., and Gray, R. (2013) W(h)ither Ecology? The Triple Bottom Line, the Global Reporting Initiative, and Corporate Sustainability Reporting. Journal of Business Ethics, 118(1), pp. 13-29.

Orlikowski, W., and Baroudi, J. (1991), "Studying Information Technology in Organizations: Research Approaches and Assumptions", Information Systems Research, Vol.2 No.1, pp.128. 
Orton-Jones, C. (2015), "Progress report: on the first anniversary of the publication of the International Integrated Reporting Council's IR framework" Financial Management (UK), February, p.36.

Parker, L and Northcott, D. (2016), "Qualitative generalising in accounting research: concepts and strategies", Accounting, Auditing \& Accountability Journal, Vol.29 No. 6, pp.100-1131.

Parrot, K.W., and Tierney, B.X. (2012), "Integrated Reporting, Stakeholder Engagement, and Balanced Investing at American Electric Power", Journal of Applied Corporate Finance, Vol.24 No.2, pp.27-37.

Perego, P., Kennedy, S., and Whiteman, G. (2016), "A lot of icing but little cake? Taking integrated reporting forward", Journal of Cleaner Production, http://dx.doi.org/10.1016/j.jclepro.2016.01.106

Phillips, D., Watson, L., and Willis, M. (2011), "Benefits of comprehensive integrated reporting", Financial Executive, Vol.27 No.2, pp.26-30.

PWC (2017), "Accountability in changing times. Analysis of FTSE 350 corporate reporting trends in 2017", available at: https://www.pwc.co.uk/audit-assurance/assets/pdf/ftse-350reporting-opportunities.pdf

Rinaldi, L., Unerman, J. and de Villiers, C. (2018), "Evaluating the integrated reporting journey: insights, gaps and agendas for future research", Accounting, Auditing \& Accountability Journal, Vol.31 No.5), pp. 1294-1318.

Reputation Dividend (2015) "The 2015 UK Reputation Dividend Report" available at: http://reputationdividend.com/files/5014/2480/0950/Summary_of_2015_UK_Reputation_Divi dend_Report.pdf

Robertson, F., and Samy, M. (2015), "Factors affecting the diffusion of integrated reporting A UK FTSE 100 perspective", Sustainability Accounting, Management and Policy Journal, Vol.6 No.2, pp.190-223.

Rogers, E.M. (2003), Diffusion of Innovations, 5th ed, NY Free Press New York.

Scott, W.R. (2001). Institutions and organizations ( $2^{\text {nd }}$ ed.), Sage ,Thousand Oaks, GA.

Silvestri, A., Veltri, S., Venturelli, A. and Petruzzelli, S. (2017), "A research template to evaluate the degree of accountability of integrated reporting: a case study", Meditari Accountancy Research, Vol. 25 No.4, pp. 675-704.

SAICA (South African Institute of Chartered Accountants) (2015), "Integrated Thinking. An Exploratory Study", available

at:<http://www.integratedreportingsa.org/Portals/0/Documents/SAICAIntegratedThinkingLan dscape.pdf

Steyn, M. (2014), "Organisational benefits and implementation challenges of mandatory integrated reporting: Perspectives of senior executives at South African listed companies", Sustainability Accounting, Management and Policy Journal, Vol.5 No.4, pp.476-503.

Stubbs, W., and Higgins, C. (2014), "Integrated Reporting and internal mechanisms of change", Accounting, Auditing \& Accountability Journal, Vol.27 No.7, pp.1068-1089.

Sturdy, A. (2004), "The adoption of management ideas and practices: Theoretical perspectives and possibilities", Management Learning, Vol.35 No.2, pp.55-179. 
Tolbert, P. S., and Zucker, L. G. (1996), "Institutionalization of institutional theory" In: Clegg, S., Hardy, C., and Nord, W.(Eds.), The Handbook of Organization Studies, Sage, Thousand Oaks: CA, pp.175-190.

Tornatzsky, L.G. and Klein, K. (1982), "Innovation Characteristics and Innovation AdoptionImplementation: A Meta-Analysis of findings" IEEE Transactions on Management, Vol.29 No.1, pp.28-45.

Westney, E. (1993), "Institutionalization theory and the multinational corporation", in Ghoshal, S., and Westney, E. (Eds.). Organization theory and the Multinational Corporation, St. Martin's Press, New York pp.53-75. 